\title{
Regulation of an iron-dependent repressor by tryptophan availability attenuates transcription of the tryptophan salvage genes in Chlamydia trachomatis
}

\author{
Nick D. Pokorzynski ${ }^{1,2}$, Nathan D. Hatch ${ }^{2}$, Scot P. Ouellette ${ }^{2}$ and Rey A. Carabeo ${ }^{2 *}$
}

The trp operon of Chlamydia trachomatis has a genetic organization that is distinct from other model bacteria. The operon contains the trpR open-reading frame (ORF), an intergenic region (IGR), and the trpB and trpA ORFs. TrpR mediates tryptophan-dependent regulation of the operon from the major promoter upstream of $\operatorname{trpR}\left(\mathrm{P}_{\text {trpR }}\right)$. We recently reported that $\operatorname{trpBA}$ is additionally regulated by the iron-dependent repressor $Y \operatorname{tgR}$ via an operator sequence within the IGR upstream of an alternative promoter for TrpR-independent $\operatorname{trpBA}$ expression $\left(\mathbf{P}_{\text {trpBA }}\right)$. Here we report that YtgR repression of $P_{t r p B A}$ is also dependent on tryptophan levels via a rare triple-tryptophan motif (WWW) in the $\mathrm{N}$-terminal permease domain of the YtgCR precursor. Tryptophan limitation inhibits translation at the WWW motif and subsequently promotes transcription termination of $y \operatorname{tg} C R$ in a Rho-independent manner. This regulatory schematic resembles mechanisms of transcriptional attenuation for trp operons described in model bacteria, such as cis-attenuation by TrpL in E. coli or trans-attenuation by TRAP in B. subtilis. YtgR performs an analogous function by sensing both iron and tryptophan levels, with the latter highlighting the unique strategy of Chlamydia to retain a trans-attenuator mechanism for regulating expression of the trpRBA operon.

Access to the amino acid tryptophan is an important determinant in the outcome of host-pathogen interactions. When infected cells are stimulated with the proinflammatory cytokine interferon-gamma (IFN $\gamma$ ), the expression of indoleamine-2,3dioxygenase (IDO1) is induced ${ }^{1}$. IDO1 catabolizes tryptophan to $\mathrm{N}$-formylkynurenine ${ }^{2}$, thereby depriving pathogens of hostderived tryptophan. Intracellular bacteria such as Mycobacterium tuberculosis and Francisella tularensis are insensitive to immunological tryptophan depletion which is dependent on their ability to biosynthesize tryptophan ${ }^{3,4}$. Surprisingly, several obligate intracellular human parasites are natural tryptophan auxotrophs, including the Gram-negative bacterium Chlamydia trachomatis (Ctr), rendering these pathogens susceptible to IFN $\gamma$ mediated tryptophan depletion ${ }^{5-8}$. This raises the intriguing question of how such pathogens respond to tryptophan deprivation to survive.

Studying the regulation of tryptophan biosynthetic operons has provided insight into fundamental aspects of gene regulation in bacteria. In the model bacterium Escherichia coli, the $\operatorname{tr} E D C B A$ operon is regulated by two complementary mechanisms: TrpR-mediated tryptophan-dependent transcriptional repression ${ }^{9}$ and TrpL-mediated tryptophandependent cis-attenuation ${ }^{10}$. TrpR repression is acutely sensitive to reduced levels of tryptophan, de-repressing the operon to induce tryptophan biosynthesis ${ }^{11}$. Attenuation, on the other hand, is relieved after severe tryptophan starvation by ribosomal stalling at a tandem tryptophan codon motif (WW) in the TrpL coding sequence ${ }^{12}$. Ribosome stalling at the WW motif promotes the formation of a transcription anti-terminator in the nascent RNA, permitting transcription of the tryptophan biosynthetic genes. Under tryptophan-replete conditions, ribosomes read through the WW motif and formation of an RNA terminator structure allows the transcription termination factor Rho to terminate downstream transcription of the operon ${ }^{13,14}$. This dual regulation greatly increases the dynamic range of trp operon expression in $E$. coli, fine-tuning their response to varying concentrations of tryptophan.

C. trachomatis, which cannot synthesize tryptophan de novo, possesses a tryptophan "salvage pathway," encoded by the $\operatorname{trpRBA}$ operon ${ }^{15}$. TrpBA is a functional tryptophan synthase that catalyzes the final step of tryptophan biosynthesis by condensing indole with serine to generate tryptophan ${ }^{16}$. The tryptophan salvage pathway is crucial in replenishing the tryptophan pool when Ctr has access to indole ${ }^{17,18}$. The organization of the $\operatorname{trpRBA}$ operon distinguishes Ctr from many other bacteria, with $\operatorname{trp} R$ encoded in the same operon as $\operatorname{trp} B A$, separated only by a 348base pair (bp) intergenic region (IGR; see Fig. 1d). The chlamydial TrpR orthologue mediates tryptophan-dependent transcriptional repression from the major promoter upstream of $\operatorname{trp} R\left(\mathrm{P}_{t r p R}\right)^{19,20}$. However, TrpR cannot regulate transcription from the $I_{G R}{ }^{20}$, despite the observation of a tryptophan-dependent transcriptional start site (TSS) for $\operatorname{trpBA}$ in this region $\left(\mathrm{P}_{\operatorname{trp} B A}\right)^{19}$, implying a more complex regulation of the operon.

Unexpectedly, the tryptophan salvage pathway is also iron-regulated in Ctr. Following iron limitation, $\operatorname{trp} B A$ is upregulated independently of altered $\operatorname{trp} R$ expression ${ }^{21,22}$. This regulation is mediated by the iron-dependent repressor YtgR, which binds to an operator sequence within the $\operatorname{trpRBA}$ IGR to repress transcription initiation from the alternative promoter for $\operatorname{trp} B A^{22}$. Simultaneously, YtgR bound to the IGR inhibits

${ }^{1}$ School of Molecular Biosciences, College of Veterinary Medicine, Washington State University, Pullman, WA, USA. ${ }^{2}$ Department of Pathology and Microbiology, University of Nebraska Medical Center, Omaha, NE, USA. *e-mail: rey.carabeo@unmc.edu 
a
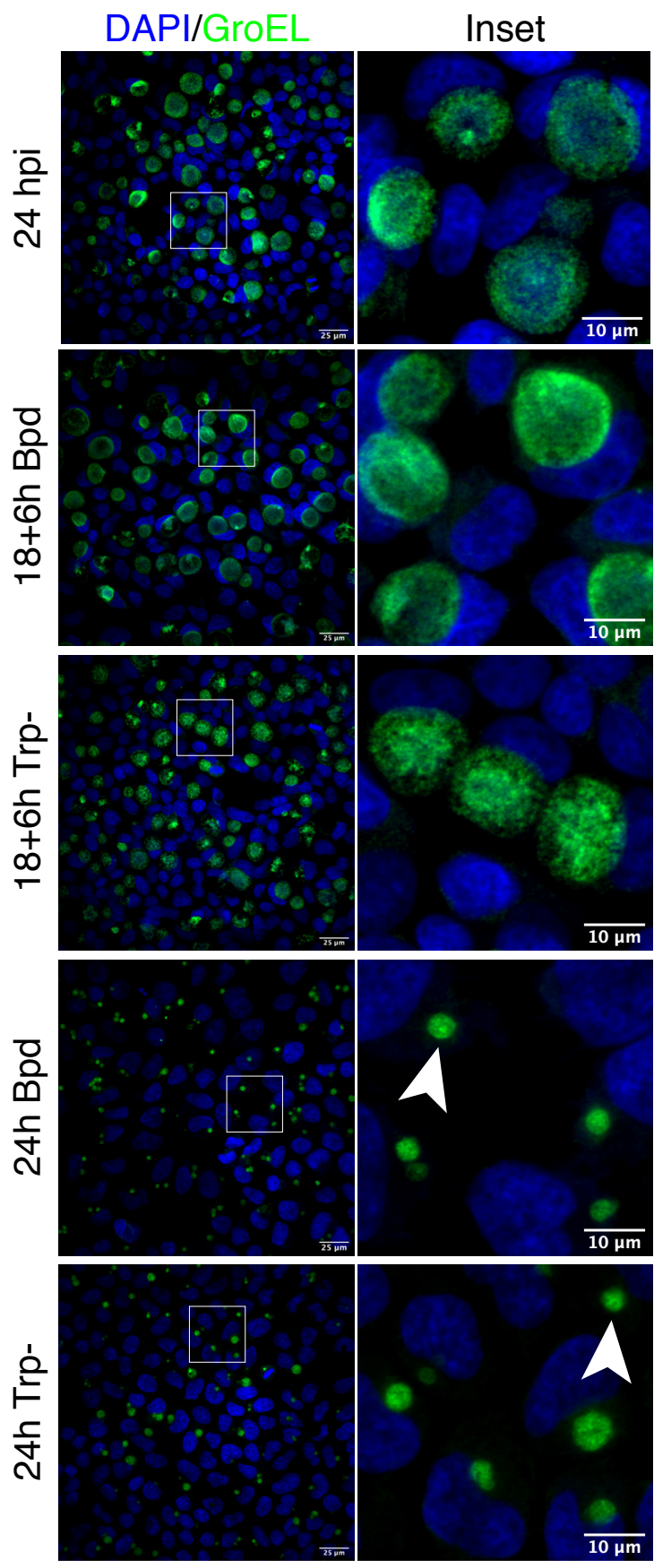

Inset

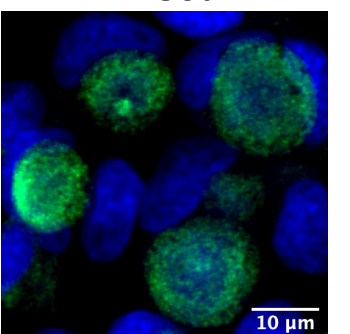

Th

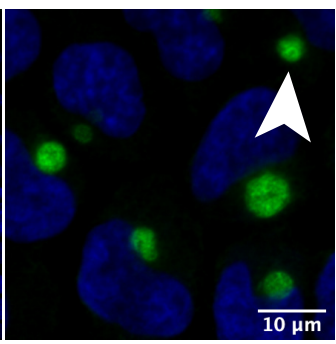

b
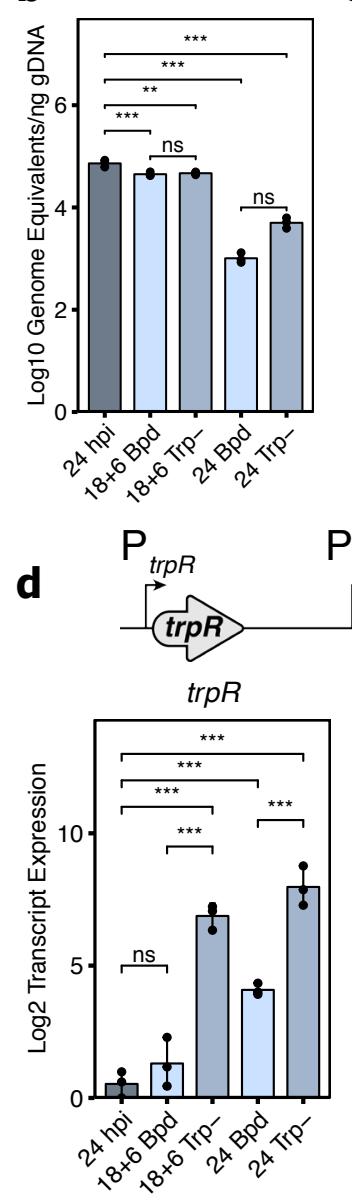

e

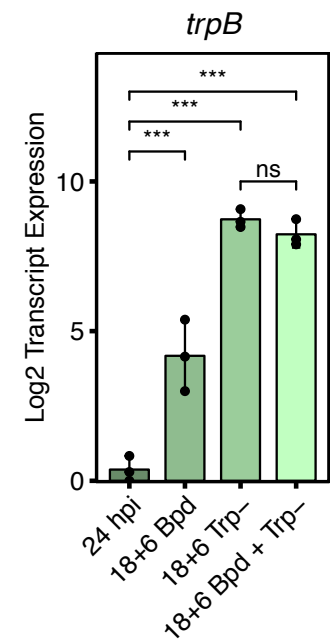

C
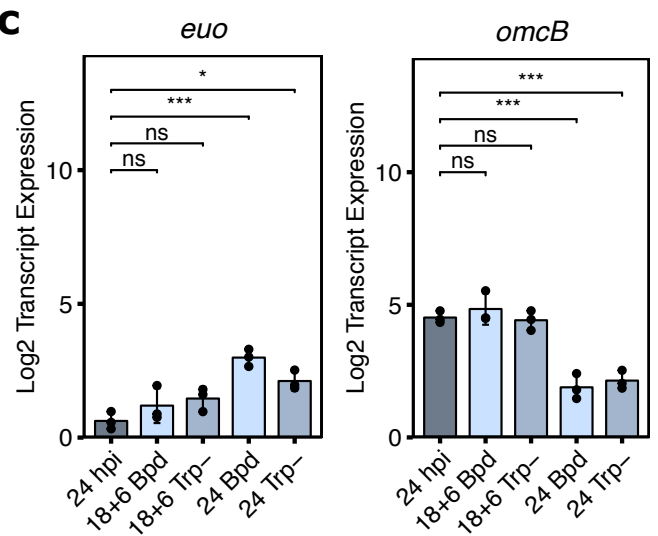

trpBA
$\vec{P}$

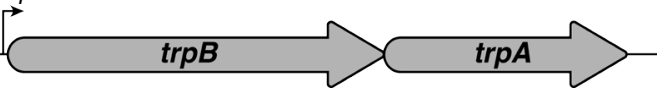

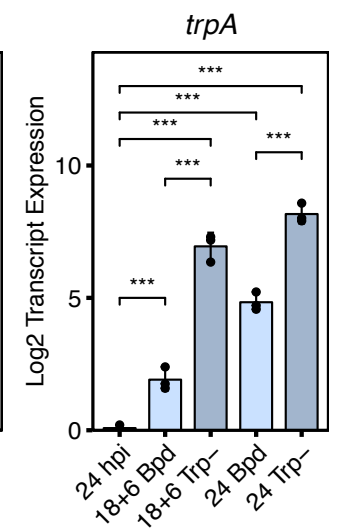

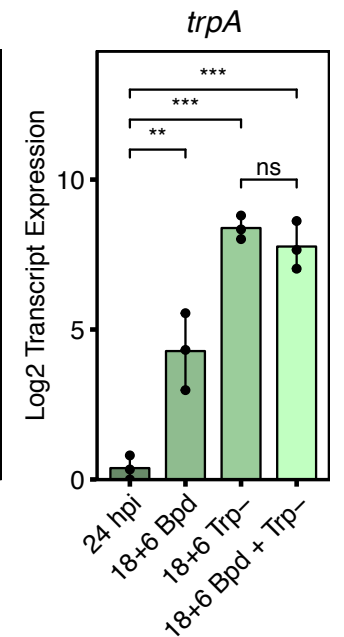

Fig. 1 | Tryptophan limitation overcomes iron-dependent repression of $\operatorname{trpBA}$. a, Representative immunofluorescent confocal micrographs of chlamydial morphology in HeLa 229 cells infected with C. trachomatis serovar L2 (434/Bu) (MOI 2) starved for iron by $100 \mu \mathrm{M} 2,2-$ bipyridyl treatment $(\mathrm{Bpd})$ or starved for tryptophan by media replacement (Trp-). C. trachomatis was visualized by detecting the cytosolic GroEL_1 - GroEL-3 antigens. Arrowheads indicate inclusions with visibly enlarged, persistent bacteria. b. C. trachomatis L2 genome copy number following iron or tryptophan starvation determined by quantitative PCR (qPCR) targeting the euo open-reading frame. c, Transcript expression of the persistence biomarkers euo and omcB. Persistence is generally characterized by an increase in euo expression and a decrease in omcB expression relative to mock treatment ( $24 \mathrm{hpi}$ ). $\mathbf{d}$, (Top) Schematic representation of the $\operatorname{tr} R B A$ operon. The major TrpR-regulated promoter $\left(\mathrm{P}_{\text {trpR }}\right)$ and alternative $Y_{\text {tgR-regulated promoter }}\left(\mathrm{P}_{t r p B A}\right)$ are annotated at their respective positions. (Bottom) Transcript expression of the trpRBA operon following either iron or tryptophan limitation. e, Transcript expression of $\operatorname{trp} B A$ following transient $6 \mathrm{~h}$ starvation of iron, tryptophan or both stresses combined. Data represent mean and s.d. of $\mathrm{N}=3$ (independent biological replicates). Statistical significance was determined by one-way ANOVA followed by Tukey's post-hoc test of honest significant differences. ${ }^{*}=p$ $<0.05,{ }^{* *}=p<0.01,{ }^{* * *}=p<0.001$. 
transcription readthrough from $P_{\text {trpR }}$. This likely benefits $C t r$ in the lower female genital tract (LGT), an environment that is both indole-rich and iron-poor. Ctr acquires iron by intercepting the vesicular recycling of the holotransferrin-transferrin receptor (TfR) complex ${ }^{23-25}$. However, TfR expression is restricted to the undifferentiated basal layers of the stratified squamous epithelium in the $\mathrm{LGT}^{26}$. Thus, Ctr may be deprived of iron during infection of the fully differentiated upper layers. Additionally, high levels of the antimicrobial iron-sequestering protein lactoferrin are associated with Ctr infections ${ }^{27-29}$. Concurrently in the LGT, colonization by various indole-producing obligate and facultative anaerobes can provide $C t r$ access to the substrate for tryptophan salvage ${ }^{30}$. Regulation of $P_{\text {trpBA }}$ by $Y \operatorname{tgR}$ may therefore perform an important function by linking the availability of iron to the anatomical site where indole is readily available to $\mathrm{Ctr}$ for tryptophan salvage.

With YtgR binding in the IGR and simultaneously interfering with transcription elongation from $P_{t r p R}$ and initiation from $\mathrm{P}_{\text {trpBA, }}$ maximal expression of the trpRBA operon during tryptophan starvation would require measures to counteract iron-dependent regulation. We therefore hypothesized that $\mathrm{Ctr}$ must possess a tryptophan-dependent mechanism for overcoming iron-dependent $\mathrm{YtgR}$ repression of $\operatorname{trpBA}$. YtgR is encoded as the $\mathrm{C}$-terminal domain of a fusion gene, $\mathrm{YtgCR}$, where the $\mathrm{N}$-terminus encodes an $\mathrm{ABC}$ transporter permease, $\mathrm{YtgC}$, from which $Y \operatorname{tgR}$ is cleaved during infection ${ }^{31,32}$. Expression of YtgR therefore requires complete expression of the upstream $\mathrm{YtgC}$ domain. Here, we report that YtgR levels are tryptophanregulated during translation through a rare motif of three sequential tryptophan codons (WWW) in the YtgC domain. Tryptophan deprivation reduces the expression of $Y \operatorname{tgR}$ in a WWW motif-dependent manner in two interrelated ways: first, ribosomes fail to read through the WWW motif and inhibit translation, and second, transcription of the YtgR-encoding sequence downstream of the WWW motif is terminated in a Rhoindependent manner following translation inhibition. The reduction in YtgR levels ultimately activates trpBA expression from $P_{t r p B A}$. This mechanism of regulation is remarkably similar to a mechanism of attenuation, where inhibition of translation at sequential tryptophan codons during periods of tryptophan starvation enables the continued transcription of downstream biosynthetic genes. We propose that $\mathrm{YtgR}$ regulation of $\operatorname{trpBA}$ exemplifies an alternative attenuation strategy in prokaryotes, where a trans-acting transcriptional regulator is subjected to regulation by tryptophan availability. This allows YtgR to customize its regulon in response to iron and/or tryptophan starvation. With YtgR functioning as a dual biosensor of iron and tryptophan, it is positioned to integrate the chlamydial stress response to two nutrients central to host nutritional immunity.

\section{Results}

Tryptophan limitation disables iron-dependent repression of trpBA expression. If tryptophan limitation inactivated irondependent $\mathrm{YtgR}$ repression of $\operatorname{trpBA}$, we expect maximal expression of trpBA during tryptophan starvation. A corollary is that the effect of iron limitation would result in elevated, but not maximal transcription of $\operatorname{trp} B A$. We tested these hypotheses by analyzing trpRBA transcript expression by reverse transcription quantitative PCR (RT-qPCR) under iron- or tryptophan-limited conditions. First, we compared expression of the operon during transient (6h) or prolonged (24h) starvation of either nutrient.

Ctr-infected cells were starved for iron or tryptophan by the addition of the iron chelator 2,2-bipyridy ${ }^{21,22,33}$ or by replacing complete media with defined media lacking tryptophan ${ }^{22}$. We expected prolonged starvation to induce chlamydial persistence, an aberrant developmental state ${ }^{34,35}$. To verify our treatment conditions, we monitored three aspects of chlamydial development: morphology, genome replication and transcription of persistence biomarkers. As expected, transient starvation did not grossly alter chlamydial morphology or the expression of the persistence biomarkers euo and omcB (Fig. 1a, 1c). We observed a significant decrease in genome replication following brief starvation, but this was very modest when compared to the prolonged starvation protocol (Fig. 1b). Indeed, prolonged persistence-inducing conditions resulted in markedly smaller inclusions with aberrantly enlarged organisms (Fig. 1a), a nearly 2 -log reduction in genome replication (Fig. 1 b) and the expected increase in euo expression with the concomitant decrease in omcB expression ${ }^{36}$ (Fig. 1c).

We then compared expression of trpRBA between our iron- and tryptophan-limited conditions. As expected, transient iron starvation specifically induced the expression of $\operatorname{trp} B A$, while trpR expression remained unchanged ${ }^{21,22}$ (Fig. 1d). In contrast, transient tryptophan limitation robustly increased the expression of $\operatorname{trpRBA} \sim 100$-fold. However, prolonged starvation revealed that iron limitation is unable to maximally induce the expression of trpRBA (Fig. 1d). We examined if this was true of other known iron-regulated genes by assaying the expression of $a h p C, \operatorname{dev} B$, $n r d A B$, and $y \operatorname{tg} A^{21,22,33,37}$. These genes all reached equivalent levels of expression following prolonged iron or tryptophan starvation (Supplementary Fig. 1). We reasoned that the unique expression of trpRBA was attributable to the dual regulation by YtgR and TrpR. While some of the iron-regulated genes we assayed (e.g. $y \operatorname{tg} A$ ) are or may be regulated by $Y \operatorname{tgR}$, we cannot discount a stress-independent regulatory mechanism that functions during persistence to up-regulate these genes. Nevertheless, their expression stands in stark contrast to that of trpRBA under the same conditions, suggesting a unique regulatory schematic for the trpRBA operon.

Next, we tested whether a transient, but combined, iron and tryptophan starvation, which would inactivate both $\mathrm{YtgR}$ and TrpR, further increased trpBA expression relative to tryptophan starvation alone. We observed that the combined stress increased trpBA expression only to the levels achieved under the tryptophan starved condition (Fig. 1e), suggesting that tryptophan limitation itself is sufficient to overcome irondependent repression. Relative to either stress alone, this combined transient stress condition did not further reduce chlamydial genome replication or produce more aberrant morphology, nor did it show transcriptional signs of persistence based on euo and omcB expression (Supplementary Fig. 2a-c). Based on these results, we hypothesized that tryptophan availability regulated the activity of $Y \operatorname{tgR}$ repression at $P_{t r p B A}$. 
a

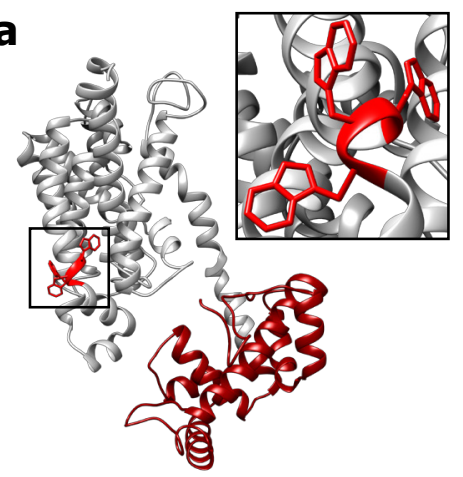

b

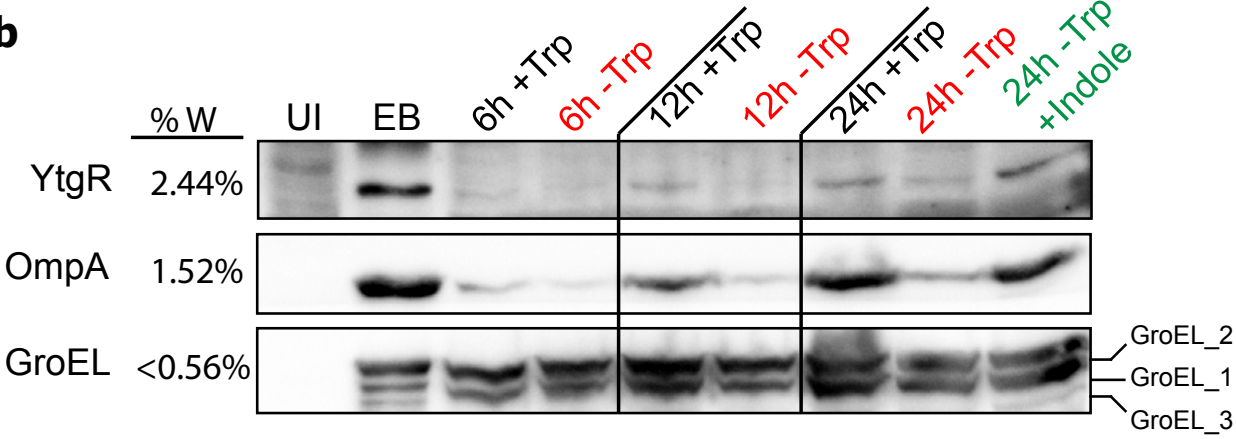

C

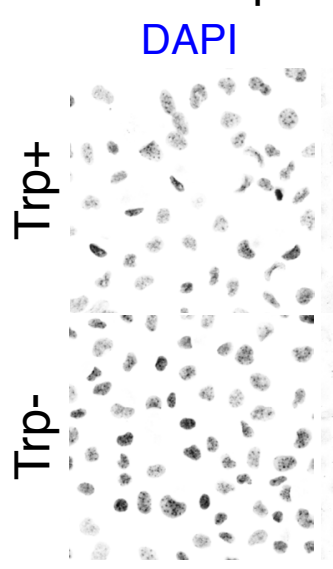

pBOMBL-YtgCR ${ }^{w w} w_{-} F L A G$

d

FLAG

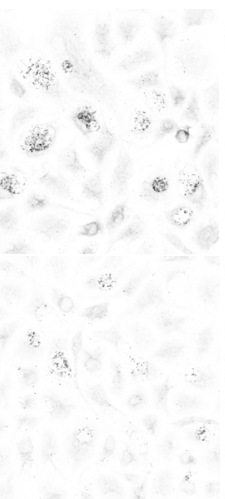

GroEL

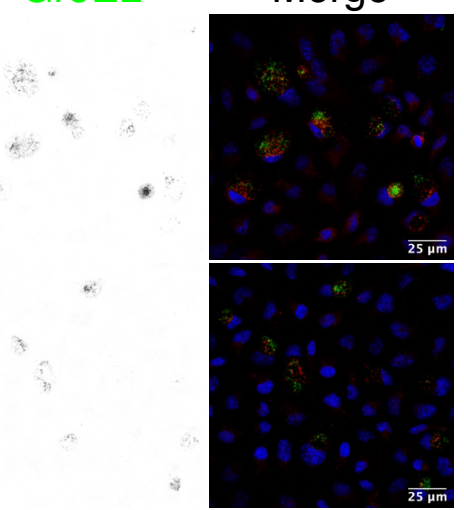

e
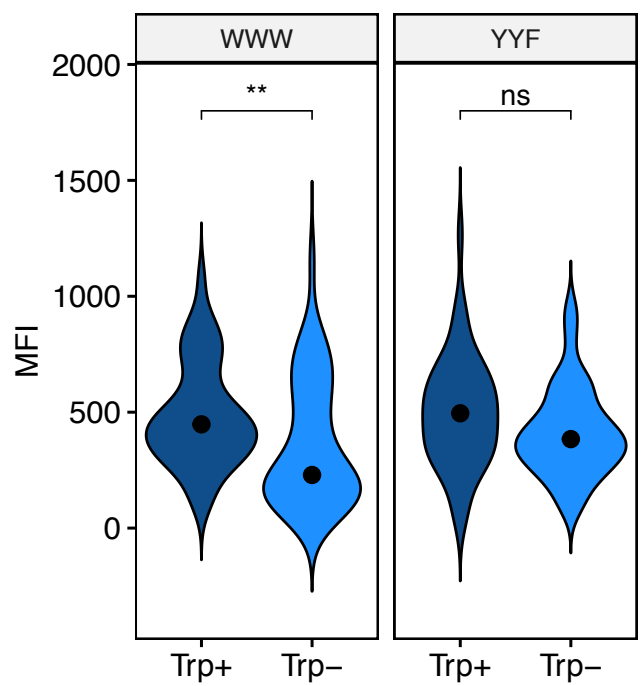

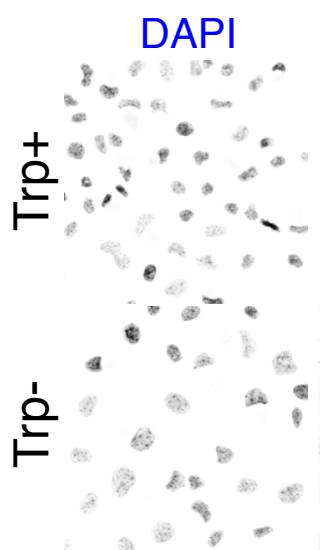

pBOMBL-YtgCR ${ }^{Y Y F}$-FLAG
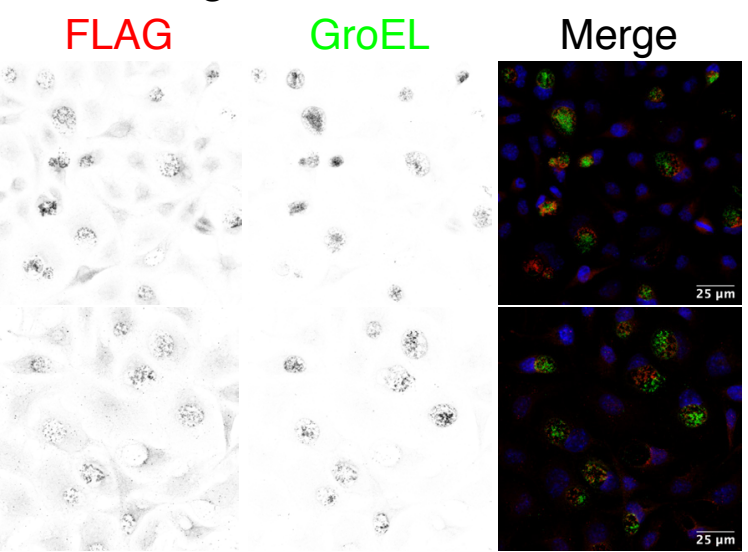

Fig. 2 | Tryptophan-dependent expression of YtgR is mediated by the WWW motif in YtgC. a, $A b$ initio structural model of YtgCR determined by the Phyre2 server. Inset shows the WWW motif. The grey region is the predicted YtgC ABC-type permease domain. The crimson region is the DtxR-like YtgR repressor domain. b. Immunoblot of YtgR expression from C. trachomatis L2-infected HeLa 229 cells (MOI 5) under tryptophan-replete (Trp+) or deplete (Trp-) conditions. Expression of tryptophan-rich OmpA and tryptophan-poor GroEL_1 - GroEL_3 were monitored as controls. Tryptophan starvation was rescued by the addition of $10 \mu \mathrm{M}$ indole to the depleted media. UI = uninfected. EB $=$ Iysate from $C$. trachomatis elementary bodies (inoculum). Equivalent volumes of lysates collected in parallel were added to each well. Image is representative of two independent experiments. c, Immunofluorescent confocal micrographs of FLAG expression from C. trachomatis L2 transformed with either pBOMBL-YtgCR ${ }^{W W W}-\mathrm{FLAG}_{\mathrm{N}}$ or $\mathbf{d}$, pBOMBL-YtgCR ${ }^{Y Y F}$-FLAG under tryptophan-replete or -deplete conditions. McCoy B mouse fibroblasts were infected at an MOI of 5 in the presence of Penicillin $\mathrm{G}$ to select for transformants. Anhydrotetracycline was added at $20 \mathrm{nM}$ to induce YtgCR-FLAG expression. GroEL was used as a counterstain to identify inclusions for quantification. Images representative of three independent experiments. e, Quantification of mean fluorescent intensity (MFI) from the FLAG channel in panels $\mathbf{c}$ and $\mathbf{d}$. Black dot in violin plots indicates the population median. Statistical significance was determined by pairwise Wilcoxon rank-sum test. ${ }^{*}=p<0.05,{ }^{* *}=p<0.01,{ }^{* *}=p<0.001$.

YtgR is regulated by tryptophan availability through the upstream WWW motif encoded in the YtgC permease domain. YtgCR is highly enriched for tryptophan codons relative to the chlamydial proteome (2.44\% versus $0.95 \%)$. Indeed, YtgCR is one of only three ORFs in the chlamydial proteome to encode a WWW motif (Fig. 2a), the other two being CTL0174 and CTL0456, putative NadC-like dicarboxylate symporters. Sequential motifs of tryptophan codons are known to play a role in connecting tryptophan availability to translation and transcription, as in transcriptional attenuation of the $E$. coli trp operon (e.g. the WW 


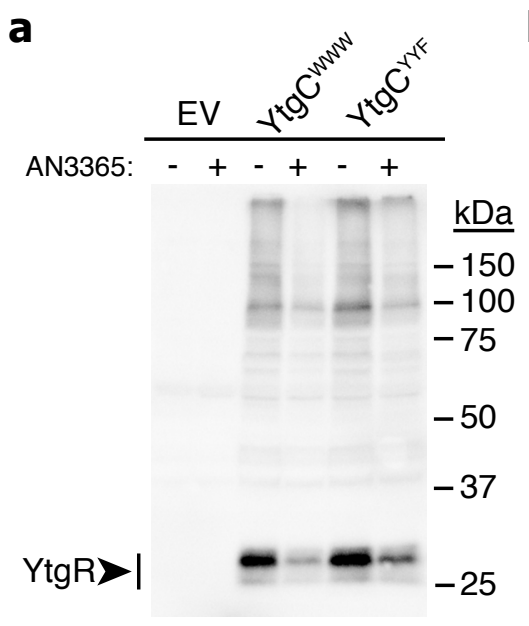

b

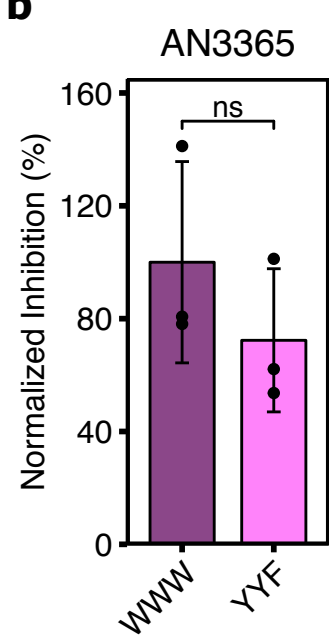

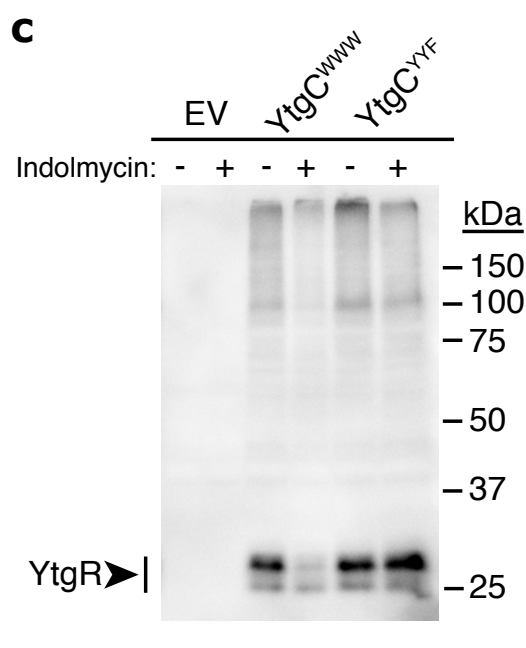

d

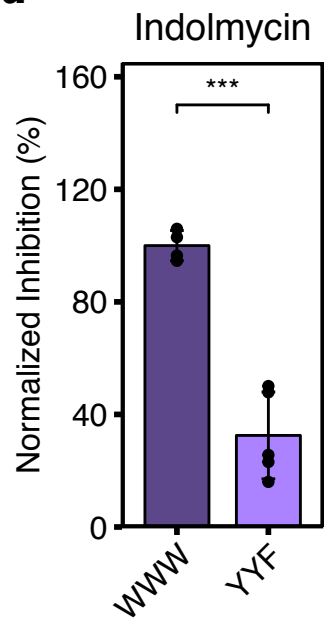

Fig. 3 | Indolmycin inhibits YtgR expression in a WWW motif-dependent manner. a, Immunoblot of pET151-YtgCR-3xFLAG (WWW or YYF) expression from BL21 (DE3) E. coli lysates in the presence or absence of $10 \mu \mathrm{g} / \mathrm{mL}$ of the leucyl-tRNA synthetase inhibitor, AN3365. Experiments were performed in M9 minimal media supplemented with $0.2 \%$ D-glucose. YtgCR-3xFLAG was detected with a monoclonal FLAG antibody. Images are representative of at least three independent experiments. b. Densitometric quantification of YtgR expression following AN3365 treatment relative to the mock treated control group and normalized to the mean of the WWW group. c. Equivalent experiment to that described in a with the exception that cultures of transformed $E$. coli were treated with $1.0 \mu \mathrm{g} / \mathrm{mL}$ of the tryptophanyl-tRNA synthetase inhibitor, indolmycin. d, Equivalent quantification to that described in $\mathbf{b}$ for indolmycin-treated experiments. Data represent mean $+/-$ s.d. of at least three independent biological replicates. Statistical significance was determined by pairwise Welch's $t$-test for unequal variance. ${ }^{*}=p<0.05,{ }^{* *}=p<0.01,{ }^{* * *}=p<0.001$.

motif in TrpL). We therefore hypothesized that the WWW motif of YtgCR may sensitize the expression of YtgR to tryptophan levels.

To test the tryptophan-dependency of YtgR expression, we analyzed the abundance of $Y \operatorname{tgR}$ in lysates from infected cells under tryptophan-replete or -deplete conditions by immunoblot (Fig. 2b). We observed that following extended tryptophan limitation, YtgR was no longer detectable in our lysates, similar to the expression of the tryptophan-rich (1.52\%) major outer membrane protein, OmpA (aka MOMP). In contrast, expression of the tryptophan-poor $(<0.56 \%)$ GroEL homologs (GroEL_1GroEL_3) was unhindered by tryptophan starvation. Notably, the expression of YtgR and OmpA was rescued by the addition of exogenous indole to the tryptophan-depleted media, implicating tryptophan starvation as the cause of reduced expression.

Under normal conditions, YtgR is expressed at very low levels and therefore difficult to detect in lysates from infected cells until late in infection. We therefore generated Ctr transformants that ectopically expressed recombinant Cterminally FLAG-tagged YtgCR from an anhydrotetracycline (aTc)inducible shuttle vector, pBOMBL (Supplementary Fig. 3a-b). Ectopic expression from these constructs thus monitors both fulllength and cleaved YtgR expression. To investigate the involvement of the WWW motif in sensitizing YtgR expression to tryptophan availability, we generated an additional transformant where the WWW motif was substituted for the hydrophobic aromatic amino acids tyrosine-tyrosine-phenylalanine (YYF). We then analyzed the expression of $\mathrm{YtgCR}^{\mathrm{WWW}}$ and $\mathrm{YtgCR}^{\mathrm{YYF}}$ under tryptophan-replete and -deplete conditions by immunofluorescent confocal microscopy (Fig. 2c-d). Cells infected with each transformant were tryptophan-starved prior to a brief aTc induction period and FLAG signal was quantified from each condition. We observed that tryptophan depletion significantly reduced the induction of $Y \operatorname{tgCR}^{W W W}$ expression, while the inducibility of YtgCR ${ }^{\text {YYF }}$ was relatively unaffected (Fig. 2e). This is notable given that the YtgR domain itself is tryptophan-rich, encoding up to six tryptophan codons. We therefore concluded that the WWW motif plays a predominant role in sensitizing the expression of $\mathrm{YtgR}$ to tryptophan availability.

Inhibition of tryptophanyl-tRNA charging by indolmycin prevents translation of YtgR in a WWW motif-dependent manner. We hypothesized that WWW motif-dependent tryptophan sensitivity in YtgCR was a consequence of translating ribosomes unable to incorporate tryptophan residues into the nascent peptide at the motif. This would occur as a function of depleted pools of charged tryptophanyl-tRNAs. To examine whether ribosome stalling at the WWW motif abrogated translation of $\mathrm{YtgR}$, we designed an expression system for $\mathrm{YtgCR}$ in E. coli, where we expressed YtgCR ${ }^{W W W}$ or YtgCR ${ }^{Y Y F}$ C-terminally tagged with a 3XFLAG epitope from the IPTG-inducible pET151 plasmid. We then took advantage of the competitive inhibitor of prokaryotic tryptophanyl-tRNA synthetase, indolmycin ${ }^{38,39}$, which prevents the incorporation of tryptophan during translation and has been shown to promote ribosome stalling at tryptophan codons $\mathrm{s}^{40}$. As a control, we included a treatment with the translation inhibitor AN3365, which functions as a noncompetitive inhibitor of prokaryotic leucyl-tRNA synthetase ${ }^{41,42}$. YtgCR contains 66 leucine residues and therefore the effect of AN3365 on YtgCR expression should be independent of any change in the WWW motif.

We transformed our YtgCR expression vectors into BL21 (DE3) E. coli and cultured them in minimal media to prevent tryptophan from outcompeting indolmycin. Concomitantly with the addition of IPTG to induce expression of YtgCR, we added 
a

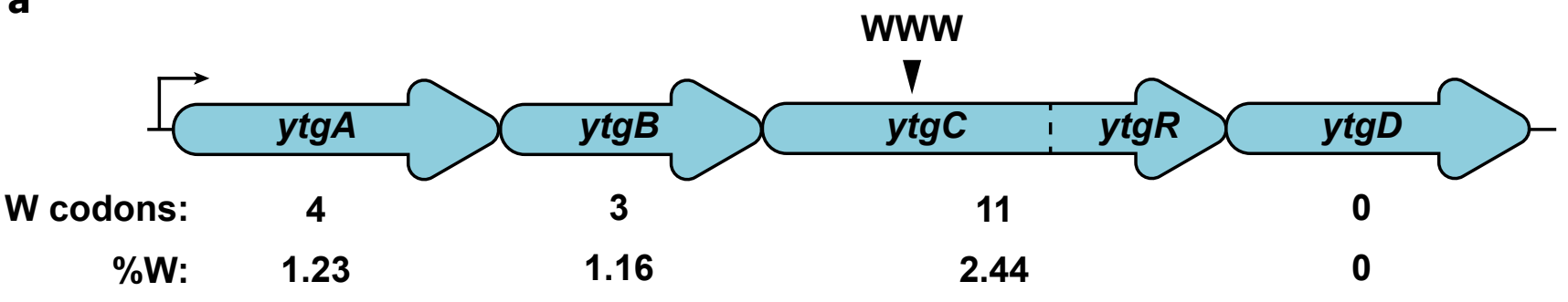

b
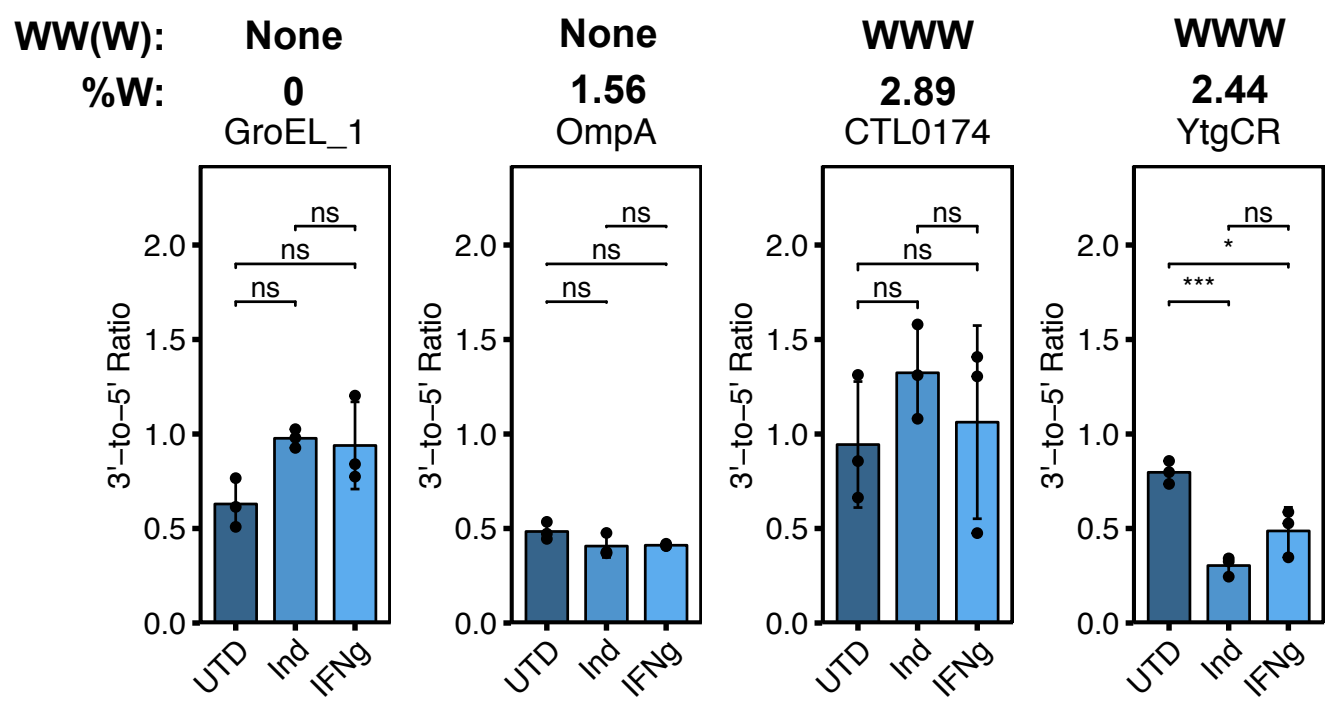

C
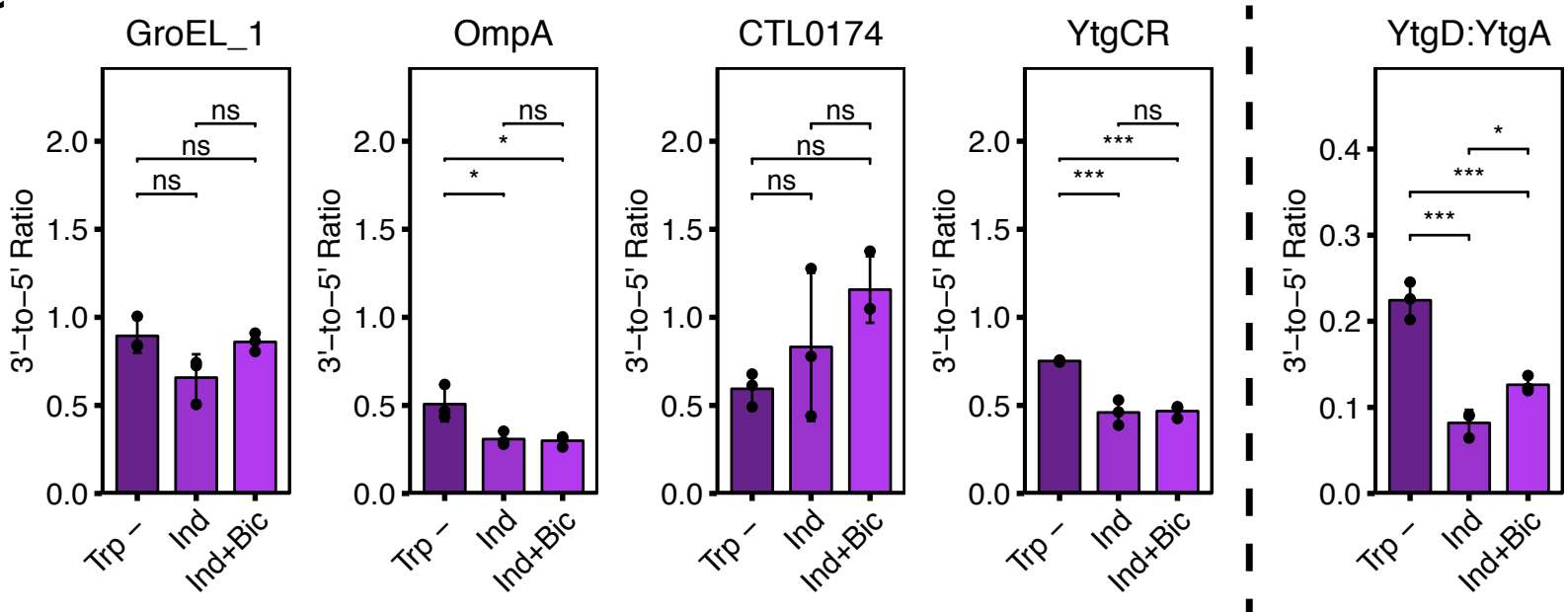

Fig. 4 | Severe tryptophan limitation terminates YtgR transcription in a Rho-independent manner. a, Schematic of the $y t g A B C D$ operon in $C$ trachomatis L2, with the tryptophan (W) codon content of each open-reading frame indicated below. The location of the WWW motif in the YtgC permease domain is indicated above the operon schematic. $\mathbf{b}$, Analysis of transcriptional polarization by RT-qPCR for YtgCR, GroEL 1, OmpA and CTL0174. C. trachomatis L2-infected HEp-2 cells were treated with either $120 \mu \mathrm{M}$ indolmycin (Ind) in tryptophan-depleted media, $0.5 \mathrm{ng} / \mathrm{mL} \mathrm{IFN} \gamma$ or left untreated (tryptophan-replete media; UTD) and transcriptional polarization was assessed by comparing 3'-to-5' gene expression. The W codon content and presence of sequential W codon motifs is indicated above the plots for each gene. Note that these samples were prepared for a prior publication ${ }^{45}$ and thus the previously reported methodology applies. c, Assessment of the involvement of the termination factor Rho in mediating transcriptional polarity for the genes described above in b. Following indolmycin treatment, $C$. trachomatis L2-infected HeLa cells were treated with $25 \mu \mathrm{g} / \mathrm{mL}$ bicyclomycin (Bic) for 4 hours to inhibit Rho activity. Tryptophan-depleted media (Trp-) was used as a reference condition to specifically discern the effect of indolmycin. Transcriptional polarity of the ytg operon (YtgD:YtgA) was included as a positive control for rescue by Rho inhibition. Note that YtgD:YtgA is displayed on a different scale due to the more pronounced difference between $y \operatorname{tg} A$ and $y \operatorname{tg} D$ expression under normal conditions. Data represent mean $+/$ - s.d. of three independent biological replicates $(N=3)$. Statistical significance was determined by One-way ANOVA followed by Tukey's post-hoc test of honestly significant differences. ${ }^{*}=p<0.05,{ }^{* *}=p<0.01,{ }^{* * *}=p<0.001$.

either indolmycin or AN3365 and then analyzed YtgR in the lysates by immunoblot with a monoclonal FLAG antibody (Fig. 3a, $3 c)$. As in Ctr, YtgCR is cleaved in E. coli and typically yields multiple cleavage products, suggesting non-specific cleavage due to dysregulated or off-target proteolytic activity ${ }^{32}$. However, in minimal media, we observed that cleavage of $Y \operatorname{tgCR}$ yielded one major band at the expected molecular weight of YtgR $(30 \mathrm{kDa})^{32}$. When we treated the transformed $E$. coli with AN3365, we observed potent inhibition of YtgCR expression irrespective of changes in the WWW motif (Fig. 3a, b). Induction of YtgCR 
resulted in a significant decrease in bacterial growth, which was partially rescued by AN3365 treatment, verifying the inhibition of YtgCR expression (Supplementary Fig. 4a). In contrast, indolmycin treatment resulted in significant inhibition of YtgR expression only in the WWW background, while expression of the YYF variant was relatively unaffected (Fig. 3c, d). Additionally, indolmycin treatment only rescued bacterial growth from the expression of $\mathrm{YtgCR}^{\mathrm{wWw}}$ and not $\mathrm{YtgCR}^{\mathrm{YYF}}$ (Supplementary Fig. 4b). Therefore, during periods of tryptophan limitation when charged tryptophanyl-tRNAs are less abundant, ribosomes likely stall at the WWW motif and restrict YtgR expression.

Indolmycin treatment inhibits transcription of YtgCR $3^{\prime}$ of the WWW motif in a Rho-independent fashion. In Chlamydia, tryptophan limitation influences the transcription of tryptophan codon-rich genes; in response to IFN $\gamma$-mediated tryptophan starvation, genes or operons enriched for tryptophan near the $5^{\prime}$ end adopt a polarized expression resulting in depletion of the $3^{\prime}$ end of the transcript ${ }^{43,44}$. One such operon that is susceptible to this regulation is the $y \operatorname{tg} A B C D$ operon, where tryptophan limitation lowers expression of $y \operatorname{tg} D$ relative to $y \operatorname{tg} A$ due to a higher abundance of $5^{\prime}$ tryptophan codons (Fig. 4a). Treatment of Chlamydia-infected cells with indolmycin also polarizes transcription of the $y t g$ operon, mimicking IFN $\gamma$-mediated depletion of host cell tryptophan pools ${ }^{45}$. This regulation is mediated by the chlamydial ortholog of the transcription termination factor Rho, whereby ribosome stalling at tryptophancodon rich regions of a transcript enables binding of Rho to rho utilization (rut) sites to terminate downstream transcription ${ }^{46}$. This parallels the role of Rho in terminating transcription during attenuation of the trp operon in E. coli. We therefore sought to interrogate the influence of chlamydial Rho in terminating transcription downstream of the WWW motif within the YtgCR ORF.

To examine whether tryptophan limitation polarized $y \operatorname{tg} C R$ transcription, we monitored transcript levels $3^{\prime}$ of the WWW motif relative to amplicon levels 5 ' of the motif by RT-qPCR in the presence of either indolmycin or IFN $\gamma$. We additionally assayed three other genes: groEL_1, which contains no tryptophan codons, ompA, which is tryptophan-rich but lacks sequential tryptophan codon motifs, and ct/0174 which is both tryptophan-rich and contains a WWW motif. For these experiments, primer sets were designed to flank the WWW motif in $y \operatorname{tgCR}$ and $c t / 0174$. For groEL_1 and ompA, amplicons were chosen that were similarly spaced to those in ytgCR and ct/0174. We observed that $y \operatorname{tg} C R$ experienced a significant 3 ' polarization downstream of the WWW motif in the presence of either indolmycin or IFN $\gamma$, whereas no other gene demonstrated tryptophan-dependent transcriptional polarity (Fig. 4b). These data suggested that the WWW motif in YtgCR uniquely coordinates translation and transcription to reduce expression of the $3^{\prime}$ end of the ORF. Interestingly, media-defined tryptophan limitation did not reproduce these results, suggesting that this effect is the consequence of severe tryptophan starvation and may depend on the depletion of host tryptophan pools in vivo (Supplementary Fig. 5).
We reasoned that the unique transcriptional polarity of $y \operatorname{tg} C R$ may be due to Rho-mediated transcription termination, given the previously reported role of Rho in the polarization of the $y \operatorname{tg}$ operon ${ }^{46}$. We first surveyed the polarization of our set of analytes in the presence of the specific inhibitor of Rho, bicyclomycin ${ }^{47,48}$, under normal growth conditions. As expected, we observed that polarization of the $y t g$ operon was reduced by Rho-inhibition; similarly, groEL_1 and ct/0174 polarization was Rho-regulated (Supplementary Fig. 6). However, polarization of $y \operatorname{tg} C R$ was unaffected by bicyclomycin, indicating that it is not a likely Rho target. Accordingly, Rho-inhibition was unable to rescue $y \operatorname{tg} C R$ polarization following indolmycin treatment, despite rescuing $y t g$ operon polarization (Fig. 4c). The polarization of genes unaffected by indolmycin or Rho inhibition were not rescued under these conditions. Transcriptional polarity of ompA was induced under these conditions, perhaps owing to the longer duration of indolmycin treatment required to include bicyclomycin treatment. However, ct/0174 did not experience the same defect, suggesting that polarization is mediated by other features of the transcript than tryptophan codon-richness alone. In total, we concluded from these data that severe tryptophan limitation reduces transcription of the $y \operatorname{tg} R$ domain $3^{\prime}$ of the WWW motif and that this occurs independently of Rho-mediated termination.

Tryptophan limitation activates the iron-dependent, YtgRregulated trpBA promoter. With tryptophan depletion reducing the levels of the YtgR repressor, it follows that the expression of genes repressed by YtgR, such as $\operatorname{trpBA}$, should be induced under the same condition. We have previously identified an YtgRregulated alternative TSS, $\mathrm{P}_{\operatorname{trp} B A}$, that expresses $\operatorname{trpBA}$ independently from $\operatorname{trp} R^{22}$. We therefore sought to understand how reducing YtgR levels in the absence of tryptophan might influence expression from $\mathrm{P}_{\text {trpBA. }}$. Using RT-qPCR and Rapid Amplification of $\underline{5^{\prime}} \underline{\underline{c} D N A} \underline{E}$ nds $\left(5^{\prime}\right.$-RACE), we investigated transcription initiation events across the trpRBA operon under iron- and tryptophan-depleted conditions.

First, we asked whether $\operatorname{trp} B$ was expressed independently of $\operatorname{trp} R$ under our validated starvation conditions (see Fig. 1) by quantifying the abundance of $\operatorname{trp} B$ transcripts (expressed from $P_{t r p R}$ and $P_{t r p B A}$ ) relative to $\operatorname{trpR}$ (expressed only from $P_{t r p R}$ ). These data were expressed as a $\operatorname{trp} B: \operatorname{trp} R$ ratio, such that a value greater than 1.0 indicates elevated expression of $\operatorname{trp} B$ independent from trpR. Normal developmental conditions indicate that $\operatorname{trp} B$ and $\operatorname{trp} R$ transcripts are expressed at relatively equal levels, indicated by a ratio near 1.0 (Fig. 5a). This could be attributable to complete transcription of the trpRBA polycistron originating at $\mathrm{P}_{t r p R}$, thus expressing equivalent $\operatorname{trp} B A$ transcripts, or expression of $\operatorname{trpR}$ from a truncated $\mathrm{P}_{\text {trpR }}$ transcript and expression of trpBA from $P_{t r p B A}$ at relatively equal levels. Contrastingly, transient or prolonged limitation of either iron or tryptophan resulted in an increase in the abundance of $\operatorname{trp} B$ relative to $\operatorname{trp} R$, suggesting that limitation of either nutrient upregulates independent expression of $\operatorname{trp} B A$, most parsimoniously explained by increased transcription from $P_{t r p B A}$. 
a

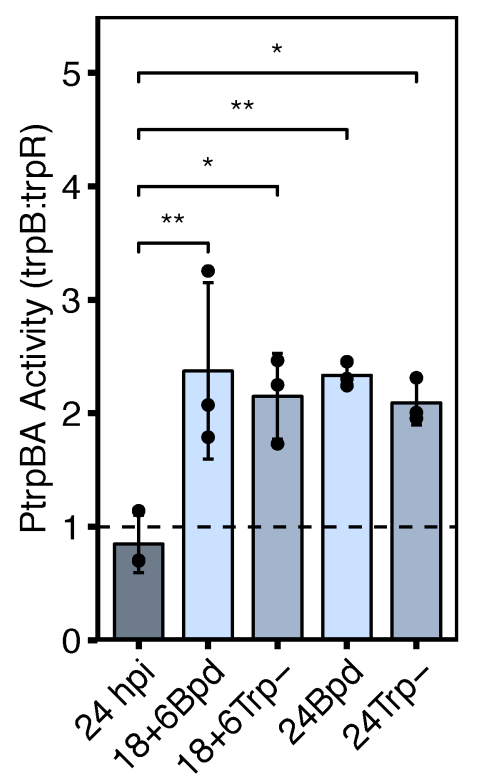

C

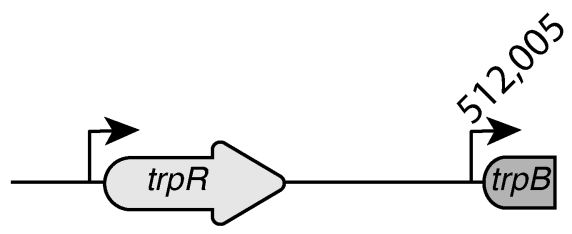

$24 \mathrm{Bpd}$

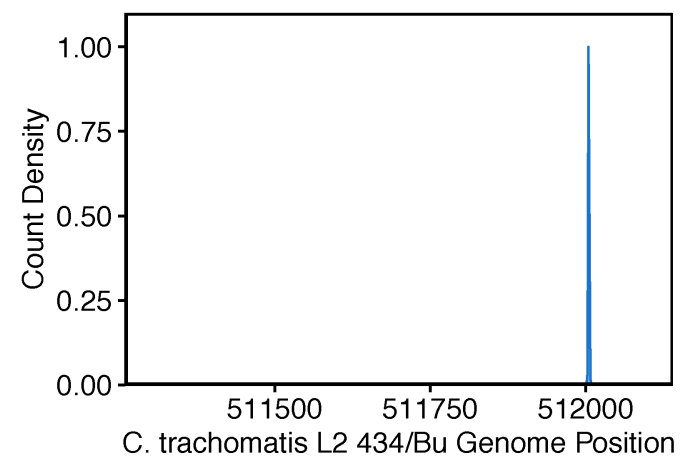

b

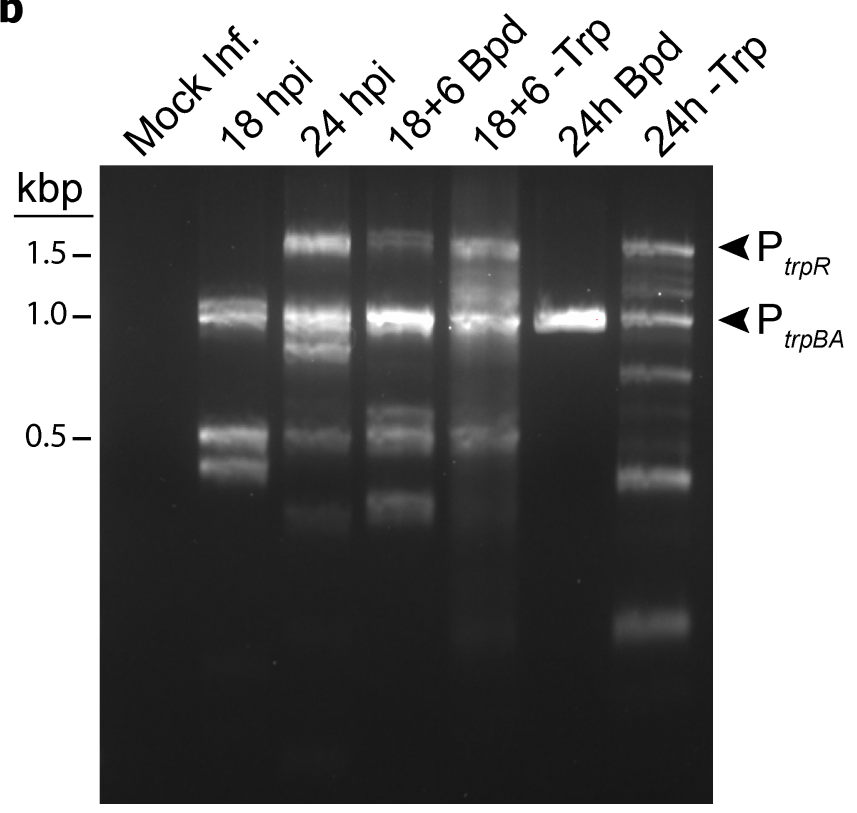

d

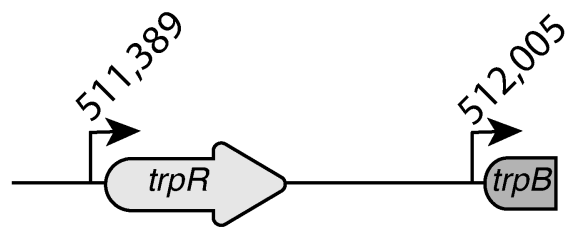

24 Trp-

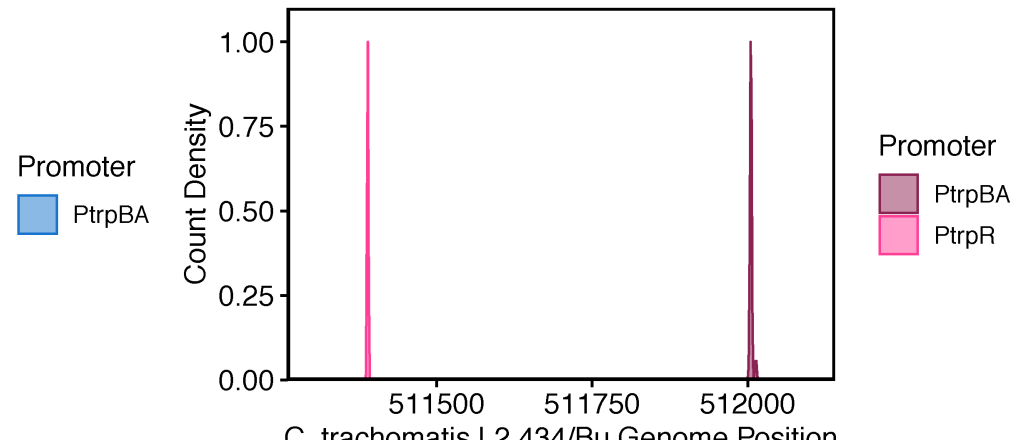

Fig. 5 | Tryptophan starvation activates the YtgR-regulated, iron-dependent promoter for trpBA. a, Assay for $\mathrm{P}_{\text {trpBA }}$ promoter activity determined by RT-qPCR comparison of $\operatorname{trpB}$-to-trpR transcript levels. Values exceeding 1.0 indicate independent expression of trpBA from the alternative promoter. b. Representative image of 5'-RACE products separated on a $2 \%$ agarose gel. The $\mathrm{P}_{\text {trpR }}$ and $\mathrm{P}_{\text {trpBA }}$ products are annotated on the right of the gel image. Note that the various apparent products below $1.0 \mathrm{~kb}$ were inconsistent across replicates and therefore treated as experimental artefacts. c, Density plot of the 5'-most nucleotide of RACE products extracted from the $24 \mathrm{~h}$ Bpd condition. A schematic of the relevant region of the trpRBA operon is depicted above the plot with the nucleotide position from the sequence population annotated above the $P_{t r p B A}$ transcriptional start site. $\mathbf{d}$, same as in $\mathbf{c}$ but for the RACE products isolated from the $24 \mathrm{~h}-T r p$ condition for both $\mathrm{P}_{t r p R}$ and $\mathrm{P}_{\text {trpBA. }}$. At least 15 isolated clones were sequenced across three replicates. Data in barplots represent mean $+/$ - s.d. of three independent biological replicates $(\mathrm{N}=3)$. Statistical significance was determined by Oneway ANOVA followed by Tukey's post-hoc test of honestly significant differences. ${ }^{*}=p<0.05,{ }^{* *}=p<0.01,{ }^{* * *}=p<0.001$.

We next determined the specific TSS for trpBA under iron- or tryptophan-depleted conditions. We amplified 5'-RACE products from Ctr-infected HeLa cells and separated them by gel electrophoresis to visualize TSS preference under our validated starvation conditions (Fig. 5b). Treatment with bipyridyl for either a transient or prolonged period yielded a 1.0-kb RACE product that mapped near $\mathrm{P}_{\text {trpBA. }}$. The same RACE product was obtained during brief and prolonged tryptophan depletion, which we attribute to reduced levels of YtgR (see Fig. 2). Unlike bipyridyl treatment, however, tryptophan depletion additionally activated the major $P_{\text {trpR }}$ promoter element due to inactivation of TrpR in the absence of the co-repressor, tryptophan. We then isolated the RACE products corresponding to $\mathrm{P}_{\text {trpR }}$ and $\mathrm{P}_{\text {trpBA }}$ following 24 hours of iron or tryptophan starvation and sequenced them to identify the TSS indicated by the $5^{\prime}$-most nucleotide from each RACE product. Iron limitation, as previously reported, induced trpBA expression from a TSS located at genome position 512,005 (Fig. 5c) ${ }^{22}$. Following tryptophan starvation, we detected trpR expression originating at 511,389, in agreement with previous reports of the TSS for $\operatorname{trpR}^{19,20,22}$ (Fig. 5d). Notably, tryptophan 

available under aCC-BY-NC-ND 4.0 International license.
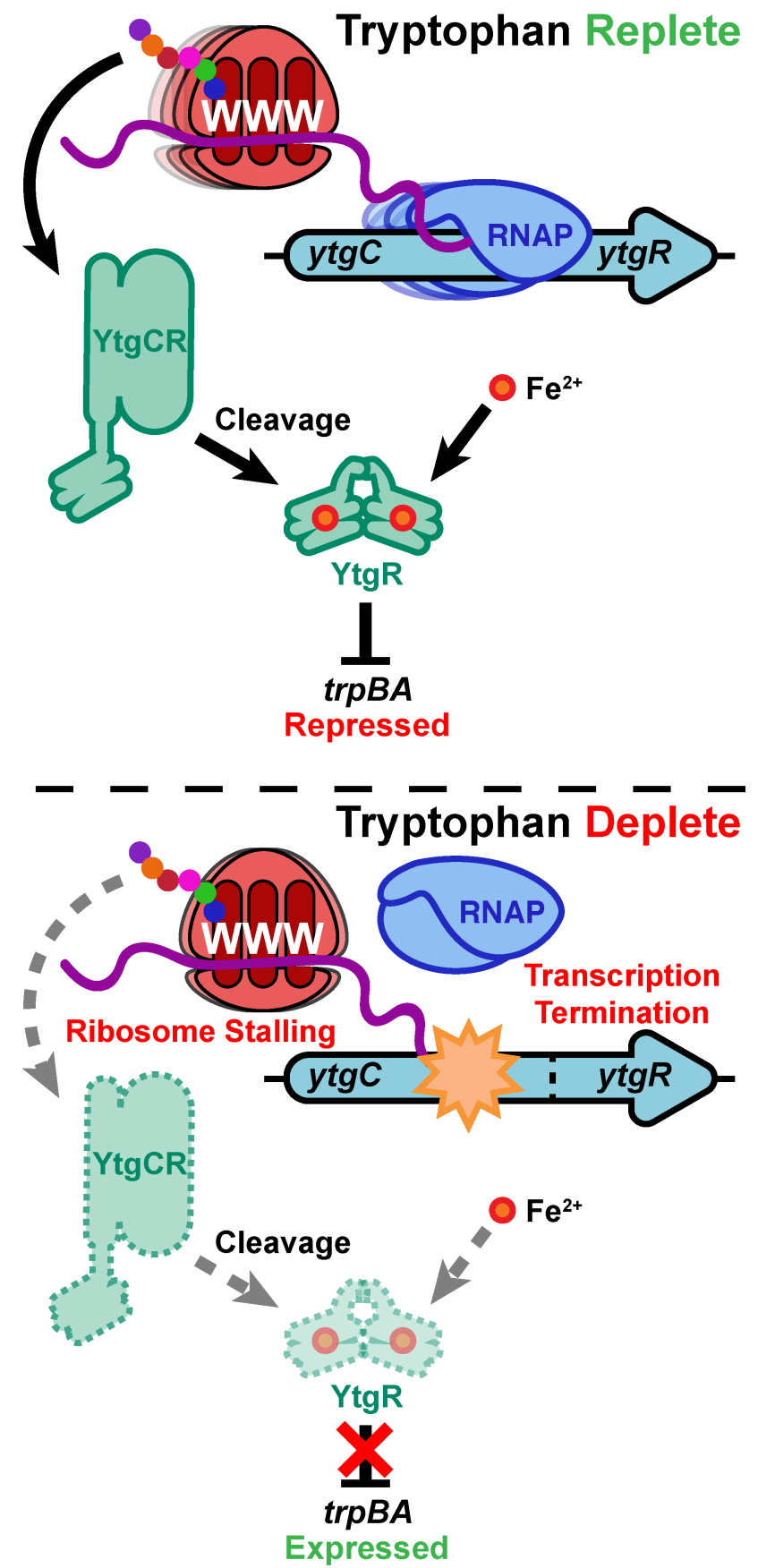

Fig. 6 | Model of tryptophan-dependent regulation of Y $\mathrm{tgR}$ expression and YtgR-mediated trpBA repression. Under tryptophan replete conditions, ribosomes are able to read through the WWW codon motif on the nascent $y \operatorname{tg} C R$ message transcribed by the RNA polymerase (RNAP) to translate the full-length YtgCR. Cleavage from YtgC allows YtgR to dimerize and coordinate iron to gain repressor functionality. YtgR then maintains repression of $\operatorname{trp} B A$ from the intergenic region. In contrast, tryptophan depletion inhibits ribosome readthrough at the WWW motif, reducing protein expression of $Y \operatorname{tgR}$ and terminating downstream transcription of the YtgR domain in a Rho-independent manner. Thus, YtgR levels are reduced and trpBA is de-repressed by $\mathrm{YtgR}$.

limitation induced $\operatorname{trp} B A$ expression from the same nucleotide position as iron limitation, 512,005. Together, these data implied that $\operatorname{trpBA}$ is transcribed from the same YtgR-regulated promoter, $\mathrm{P}_{\text {trpBA, }}$ in response to both iron and tryptophan limitation.

\section{Discussion}

These data collectively point to a model where tryptophan deprivation limits the level of the YtgR repressor to activate transcription from the alternative YtgR-regulated promoter for $\operatorname{trpBA}$ (Fig. 6). YtgR translation is regulated by tryptophan through the upstream WWW motif in the YtgC permease domain to reduce availability of the repressor under tryptophan-starved conditions, thereby de-repressing trpRBA. This regulatory mechanism parallels cis-attenuation by $\operatorname{TrpL}$ in $E$. coli, though notable differences exist: namely, this attenuation mechanism functions in trans through a transcription factor. While we have focused here on the comparison of YtgCR to TrpL, other mechanisms of attenuation exist. Bacillus subtilis, which lacks a TrpR orthologue, has a comparable but distinct attenuation mechanism, where the oligomeric RNA-binding TRAP protein functions in trans to sequester the leader RNA of the trp operon in a tryptophan-dependent manner ${ }^{49}$, thereby attenuating expression of the structural genes of the operon. TRAP-mediated attenuation functions with the same regulatory logic as YtgCR and TrpL, yet through a highly specialized mechanism that does not closely parallel either. It is interesting to note, however, that both TRAP and YtgCR function in trans, suggesting the convergent evolution of similar logics for trp operon attenuation in highly dissimilar organisms.

An outstanding question is the role of possible cisattenuation in the $\operatorname{trpRBA}$ operon. A putative trpL leader peptide (TrpL ${ }^{C t r}$ ) has been annotated in the trpRBA IGR in the Ctr genome ${ }^{50,51}$, but it has not been experimentally validated. $\operatorname{Trp} \mathrm{L}^{\mathrm{Ctr}}$ was inferred from the prediction of alternating RNA hairpin structures upstream of $\operatorname{trp} B A^{50}$, but has many atypical characteristics. Unlike putative TrpL peptides in other bacteria, $\mathrm{TrpL}^{\mathrm{Ctr}}$ is annotated as an unusually long 59 amino acid peptide with non-consecutive tryptophan codons, thus lacking a signature sequential tryptophan codon motif (Supplementary Data 1). In silico analysis of the IGR by the PASIFIC algorithm ${ }^{52}$ indicates that this sequence would form a poor attenuator and it predicts transcript termination before the end of the annotated leader peptide ORF (Supplementary Fig. 7). We suggest the possibility that the evolutionary gain of the $\mathrm{YtgR}$ operator sequence in the trpRBA IGR may have led to the degeneration of TrpL function as YtgR was able to maintain tryptophandependent regulation of $\operatorname{trpRBA}$. Future studies will be aimed at elucidating the true function, if any, of the putative trpL in Ctr.

A final interesting consideration is the broader role of YtgR regulation in chlamydial development. As a biosensor for both tryptophan and iron levels, YtgR may be critical to maintenance of normal gene expression throughout the chlamydial developmental cycle as it siphons nutrients from the host cell. The WWW motif of YtgCR is highly conserved across the Chlamydiaceae but poorly conserved among the environmental chlamydiae in the Chlamydiales order (Supplementary Fig. 8a). In contrast, the WWW motif of CTL0174 is perfectly conserved across the Chlamydiales, including in Waddlia chondrophila and Parachlamydia acanthamoebae (Supplementary Fig. 8b). This suggests that the YtgCR WWW motif may have been gained in adaptation to mammalian hosts. This is further supported by the 
bioRxiv preprint doi: https://doi.org/10.1101/2020.05.03.075317; this version posted May 3, 2020. The copyright holder for this preprint (which was not certified by peer review) is the author/funder, who has granted bioRxiv a license to display the preprint in perpetuity. It is made available under aCC-BY-NC-ND 4.0 International license.

observation that among the four avian chlamydiae included in our analysis, only two contain complete WWW motifs in YtgCR. Discerning the regulatory function of YtgR among chlamydial species may reveal important insights into the evolutionary trajectory of the Chlamydiales and the adaptation of Ctr to life as a human pathogen.

\section{Methods}

Eukaryotic cell culture and chlamydial infections. Human cervical epithelial adenocarcinoma HeLa cells were cultured at $37^{\circ} \mathrm{C}$ with $5 \%$ atmospheric $\mathrm{CO} 2$ in Dulbecco's Modified Eagle Medium (DMEM; Gibco, Thermo Fisher Scientific, Waltham, MA, USA)) supplemented with $10 \mu \mathrm{g} / \mathrm{mL}$ gentamicin, $2 \mathrm{mM} \mathrm{L}$ glutamine, and $10 \%(\mathrm{v} / \mathrm{v})$ filter sterilized fetal bovine serum (FBS). For all experiments, HeLa cells were cultured between passage numbers 3 and 15 . McCoy B mouse fibroblasts (originally from Dr. Harlan Caldwell, NIH/NIAID) were cultured under identical conditions. Chlamydia trachomatis serovar L2 (434/Bu) was originally obtained from Dr. Ted Hackstadt (Rocky Mountain National Laboratory, NIAID). Chlamydial EBs were isolated from infected HeLa cells at 36$40 \mathrm{hr}$ post-infection (hpi) and purified by density gradient centrifugation essentially as described ${ }^{53}$.

For infections, at $80-90 \%$ confluency, cells were first washed with Hanks Buffered Saline Solution (HBSS; Gibco, Thermo Fisher Scientific) and icecold inoculum prepared in HBSS at the indicated multiplicity of infection was overlaid onto the cell monolayer. To synchronize the infection, inoculated cells were then centrifuged for $15 \mathrm{~min}$ at 500xRCF, $4^{\circ} \mathrm{C}$ in an Eppendorf $5810 \mathrm{R}$ tabletop centrifuge with an A-4-81 rotor. The inoculum was then aspirated and pre-warmed DMEM (or relevant media with treatment supplementation) was added to the cells. Infected cultures were then returned to the tissue culture incubator until the indicated time post-infection.

Treatment conditions. For iron starvation and media-defined tryptophan starvation, treatment was performed essentially as described previously22. In brief, 100 mM 2,2-bipyridyl (Sigma Aldrich, St. Louis, MO, USA; CAS: 366-18-7) prepared in dimethyl sulfoxide (DMSO) was added to complete DMEM (or tryptophan-depleted DMEM-F12, as described below) at a working concentration of $100 \mu \mathrm{M}$ at the start of infection (24h) or at $18 \mathrm{hpi}(18+6 \mathrm{~h})$. When added after the time of infection, cells were first washed with HBSS prior to bipyridyl treatment. Tryptophan depletion was performed by first washing cells with HBSS and then replacing complete DMEM with tryptophan-depleted DMEM-F12 (U.S. Biological Life Sciences, Salem, MA, USA). Media was replaced either at the time of infection (24h) or at $18 \mathrm{hpi}(18+6 \mathrm{~h})$. For immunoblotting, tryptophan starvation began at $12 \mathrm{hpi}$ and samples were collected at the indicated time-points. Indole supplementation was performed by adding $10 \mu \mathrm{M}$ indole (prepared as $10 \mathrm{mM}$ stock in $100 \%$ ethanol) to the tryptophan-depleted media at the time of replacement. For analysis of YtgCR-FLAG expression from transformed $C$. trachomatis strains, 16 hour tryptophan starvation began at $8 \mathrm{hpi}$. Tryptophandepleted media was supplemented as described for DMEM with the exception that the FBS was dialyzed in a $10 \mathrm{kDa}$ MWCO dialysis cassette (Thermo Fisher Scientific) for $16-20$ hrs at $4^{\circ} \mathrm{C}$ in $4 \mathrm{~L}$ of PBS. Treated cells were then returned to the tissue culture incubator for the remainder of the experimental time course.

For cell culture experiments, indolmycin treatment was performed essentially as described previously ${ }^{45}$. In brief, $120 \mathrm{mM}$ indolmycin (Cayman Chemical, Ann Arbor, MI, USA; CAS: 21200-24-8) prepared in DMSO was added to tryptophandepleted DMEM-F12 at a working concentration of $120 \mu \mathrm{M}$ at $8 \mathrm{hpi}$ and proceeded for 16 or $20 \mathrm{hrs}$.

Bicyclomycin treatments were performed essentially as described previously ${ }^{46}$. In brief, $25 \mathrm{mg} / \mathrm{mL}$ bicyclomycin benzoate (Cayman Chemical; CAS: 37134-40-0) prepared in DMSO was added to infected cell cultures at a working concentration of $25 \mu \mathrm{g} / \mathrm{mL}$ at $24 \mathrm{hpi}$ (16h after addition of indolmycin) and treatment was allowed to proceed for $4 \mathrm{hrs}$. For the initial survey of Rhodependent regulation among the assayed genes, bicyclomycin was added at 18 hpi and treatment was allowed to proceed for $6 \mathrm{hrs}$.

Nucleic acid preparation. RNA was harvested from C. trachomatis-infected cells by scraping one or two wells of a 6 -well tissue culture plate in a total volume of $500 \mu \mathrm{L}$ Trizol Reagent (Thermo Fisher Scientific). Samples were transferred to RNase-free o-ring capped tubes containing $\sim 100 \mu \mathrm{L}$ volume of zirconia beads and thoroughly vortexed for $10 \mathrm{~min}$ to rupture bacterial cells. Zirconia beads were pelleted by centrifugation at $21,000 \times \mathrm{xg}$ for $10 \mathrm{~min}$ at $4^{\circ} \mathrm{C}$ and supernatant was transferred to an RNase-free tube containing $100 \mu \mathrm{L}$ chloroform (Sigma Aldrich). Samples were vortexed for $15 \mathrm{~s}$ prior to a $10 \mathrm{~min} \mathrm{RT}^{\circ} \mathrm{C}$ incubation. Phases were then separated by centrifugation at $21,000 \times \mathrm{xg}$ for $15 \mathrm{~min}$ at $4^{\circ} \mathrm{C}$. The aqueous top layer was transferred to an RNase-free tube containing $250 \mu \mathrm{L} \mathrm{100 \%} \mathrm{ethanol} \mathrm{to}$ precipitate RNA. Samples were briefly vortexed and then applied to an RNA collection column provided in the PureLink ${ }^{T M}$ RNA Mini Kit (Invitrogen, Thermo Fisher Scientific). RNA was isolated as described by the manufacturer with an oncolumn DNA digestion using the PureLink ${ }^{\mathrm{TM}}$ DNase Set (Invitrogen, Thermo Fisher Scientific). RNA was eluted in nuclease-free $\mathrm{H}_{2} \mathrm{O}$ and stored at $-20^{\circ} \mathrm{C}$ for shortterm storage or $-80^{\circ} \mathrm{C}$ for long-term storage.

Complementary DNA (cDNA) was generated using 1-2 $\mu \mathrm{g}$ of RNA as a template for the SuperScript IV Reverse Transcriptase (RT) VILO master mix (Invitrogen, Thermo Fisher Scientific) with a no-RT control reaction in a halfreaction volume following manufacturer protocols. The no-RT control sample was screened for DNA contamination by end-point PCR targeting the $C$. trachomatis L2 ompA ORF. For RACE experiments, CDNA was generated following the SMARTer ${ }^{\circledR} 5$ '/3' RACE kit protocol (Takara Bio, Kusatsu, Shiga Prefecture, Japan).

Genomic DNA (gDNA) was harvested from parallel well(s) of a 6-well plate in $200 \mu \mathrm{L}$ ice-cold PBS $+10 \%$ Proteinase $K$ and processed through the DNeasy Blood and Tissue Kit following manufacture protocols (QIAGEN, Hilden, Germany). gDNA was stored at $-20^{\circ} \mathrm{C}$ for short-term storage or $-80^{\circ} \mathrm{C}$ for long-term storage.

Quantitative PCR. All quantitative PCR (qPCR) assays were performed using Power U ${ }^{T M}$ SYBR $^{T M}$ Green Master Mix (Applied Biosystems, Thermo Fisher Scientific) essentially as previously described ${ }^{22}$. In brief, cDNA was diluted 1:5-1:10 and gDNA was diluted 1:50-1:100 in nuclease-free $\mathrm{H}_{2} \mathrm{O}$ (dilutions were identical within each experiment). The $2 X \mathrm{XCR}$ master mix was diluted to $1 \mathrm{X}$ in nucleasefree $\mathrm{H}_{2} \mathrm{O}$ with specific primers diluted to $500 \mathrm{nM}$ (see Supplementary Table 1 for complete list of primers). To $79 \mu \mathrm{L}$ of the master mix solution, $3.3 \mu \mathrm{L}$ of template (cDNA or gDNA) was added and then aliquoted into three $25 \mu \mathrm{L}$ technical replicate reactions in a 96-well optical plate. Reactions were analyzed on an Applied Biosystems 7300 Real Time PCR System or a QuantStudio ${ }^{\text {TM }} 3$ Real-Time PCR System with standard SYBR cycling conditions. All assays were performed with a melt-curve analysis to ensure specific product amplification across samples. All primer sets used in qPCR were validated against a standard curve of $C$. trachomatis $\mathrm{L} 2 \mathrm{gDNA}$ diluted from $2 \times 10^{-3}$ to $2 \times 10^{0} \mathrm{ng}$ per reaction. $C_{t}$ values generated from each experimental reaction were then fit to a standard curve and only primer sets with an efficiency of $100 \%+/-5 \%$ were used. All primer pairs were validated for specific product amplification by melt-curve analysis and gel electrophoresis of amplified products.

Genome equivalents (GE) were calculated by first converting the mean $\mathrm{C}_{\mathrm{t}}$ of the triplicate technical replicate reactions to a ng quantity of gDNA (ng template) with the linear equation generated from the standard curve of the euo primer pair. This value was then normalized to the total $\mathrm{ng} / \mu \mathrm{L}$ gDNA isolated for each sample as follows:

$$
G E=\frac{n g \text { template }}{\frac{n g}{\mu L} g D N A}
$$

Transcript expression (TE) normalized to genome equivalents was calculated as follows:

$$
T E=\frac{2^{\left(C t_{G E}-C t_{T E}\right)}}{\frac{n g}{\mu L} g D N A}
$$

Where $C_{t}(G E)$ is the $C_{t}$ value of genome equivalents from the respective sample, $C_{t}(T E)$ is the $C_{t}$ value from the cDNA for the same sample and $\mathrm{ng} / \mu \mathrm{L}$ gDNA is the concentration of gDNA from that sample. These values were then scaled such that the lowest value across the biological replicates equaled 1.0 for aesthetic purposes. The scaled values were then Log2-transformed to enable the statistical comparison of values that varied widely in magnitude (e.g. trpRBA expression following tryptophan starvation vs. bipyridyl treatment). When different dilution factors were used between replicates, $C_{t}(G E)$ and $C_{t}(T E)$ were corrected for dilution.

Calculation of $3^{\prime}$-to-5' ratio and the $\operatorname{trpB}: \operatorname{trpR}$ ratio was performed as follows:

$$
\text { Ratio }=2^{C t(R e f)-C t(E x p)}
$$

Where $C_{t}\left(\right.$ Ref) is the $C_{t}$ value of the reference amplicon (e.g. $5^{\prime}$ or trpR) and $C_{t}(\operatorname{Exp})$ is the $C_{t}$ value of the experimental amplicon (e.g. $3^{\prime}$ or $\left.\operatorname{trpB}\right)$.

Immunofluorescent confocal microscopy. To analyze inclusion morphology, HeLa cells were seeded onto acid-washed glass coverslips in 24-well tissue culture plates and infected at $\mathrm{MOI}=2$. At the indicated times post-infection, coverslips 
were washed with phosphate-buffered saline (PBS) and cells were fixed with $4 \%$ paraformaldehyde in PBS for $15 \mathrm{~min}$ at $\mathrm{RT}^{\circ} \mathrm{C}$. Fixation solution was then aspirated and coverslips were either stored at $4^{\circ} \mathrm{C}$ in PBS or immediately processed for immunofluorescence assays by permeabilizing cells in PBS $+0.2 \%$ Triton X-100 (Thermo Scientific ${ }^{\mathrm{TM}}$ ) for $10 \mathrm{~min}$ at $\mathrm{RT}^{\circ} \mathrm{C}$ with rocking. Permeabilization solution was then decanted and coverslips were washed $3 x$ with PBS. Coverslips were blocked in PBS $+3 \%$ bovine serum albumin (BSA) for $1 \mathrm{hr}$ at $\mathrm{RT}^{\circ} \mathrm{C}$ with rocking. Coverslips were then washed $3 \mathrm{x}$ with PBS prior to being overturned on a $50 \mu \mathrm{L}$ droplet of PBS $+3 \%$ BSA containing primary antibody diluted 1:1000. To detect chlamydial GroEL, cells were stained with monoclonal mouse anti-cHsp60 (MA3023, Invitrogen, ThermoFisher Scientific). Coverslips were incubated on primary antibody solution overnight at $4^{\circ} \mathrm{C}$ in an opaque humidified container. Coverslips were then washed thoroughly by repeated submersion ( $50 \mathrm{x})$ in $100 \mathrm{~mL}$ PBS before being overturned on a $50 \mu \mathrm{L}$ droplet of PBS $+3 \%$ BSA + 1:1000 secondary antibody $+2.5 \mu \mathrm{g} / \mathrm{mL} \mathrm{4}$, 6 -diamidino-2-phenylindole (DAPI) to label nuclei. A donkey anti-mouse AlexaFluor-488 secondary antibody (Invitrogen, Thermo Fisher Scientific) was used to label the primary mouse anti-cHsp60. Coverslips were then incubated for at least one hour at $\mathrm{RT}^{\circ} \mathrm{C}$ in an opaque humidified container prior to being washed as described above in Milli- $\mathrm{H}_{2} \mathrm{O}$ and then being mounted on glass microscope slides with $10 \mu \mathrm{L}$ Shandon $^{\mathrm{TM}}$ Immu-Mount (Thermo Fisher Scientific). Mounting medium was allowed to solidify overnight. Confocal microscopy was performed on a Nikon Ti2 Eclipse spinning-disk confocal microscope. All images were acquired using identical laser power and exposure settings. To enhance visualization of inclusion morphology, contrast and brightness were adjusted as necessary for each condition in Fiji Image ${ }^{54}$. All images are summed Z-projections of Z-stacks spanning the entire depth of the inclusions in the field.

Structural modeling of YtgCR. The amino acid sequence of CTL0325 (YtgCR) from the C. trachomatis L2 434/Bu genome (NCBI Accession: NC_010287) was submitted to the Phyre2 server using "Intensive" modelling mode ${ }^{55}$. The resultant .pdb file was then visualized on the UCSF Chimera software and edited as shown ${ }^{56}$.

Immunoblotting. Lysates of infected HeLa cells were prepared by scraping three wells of a 6-well plate into 300-500 $\mu \mathrm{L}$ volume of ice-cold Mammalian Protein Extraction Reagent (M-PER ${ }^{\mathrm{TM}}$ ) buffer (Thermo Fisher Scientific) supplemented with cOmplete ${ }^{\mathrm{TM}}$ Mini EDTA-free Protease Inhibitor Cocktail (Roche, Basel, Switzerland). Scraped cells were allowed to incubate on ice in lysis buffer for 30 min prior to the addition of $1 X$ concentration of Laemmli SDS buffer. Samples were then boiled at $95^{\circ} \mathrm{C}$ for $10 \mathrm{~min}$ prior to centrifugation at $21,000 \mathrm{xg}$ for 10 $\mathrm{min}, 4^{\circ} \mathrm{C}$ to pellet debris. Lysates were stored at $-80^{\circ} \mathrm{C}$.

Equal volumes of lysate were then separated by gel electrophoresis on a $12 \%$ acrylamide gel in Tris-Glycine-SDS buffer for 1.5 hours at $150 \mathrm{~V}$ (constant voltage) on a Bio-Rad PowerPac ${ }^{T M}$ HC High-Current Power Supply. Blotting to 0.45 $\mu \mathrm{m}$ nitrocellulose membrane was performed on a Bio-Rad Trans-Blot ${ }^{\circledR}$ SD SemiDry Transfer Cell with Bjerrum and Schafer-Nielsen transfer buffer (48 mM Tris, $39 \mathrm{mM}$ glycine, $20 \%$ Methanol $(\mathrm{v} / \mathrm{v})$ ) for $60-70 \mathrm{~min}$ at $20 \mathrm{~V}$ (constant voltage). The membrane was then equilibrated in Tris-buffered saline $+0.1 \%$ Tween-20 (TBS-T) prior to blocking in TBS-T + 5\% non-fat dry milk (NFDM) for 1 hour at $\mathrm{RT}^{\circ} \mathrm{C}$ with rocking. Membrane was then washed with TBS-T and TBS-T + 5\% NFDM + 1:5001:1000 primary antibody was added. For detecting $Y \operatorname{tgR}$, a polyclonal rabbit antibody was raised against the final 49 C-terminal residues of the YtgCR ORF (Li International, Denver, CO, USA). OmpA was detected with a monoclonal mouse antibody (a generous gift of Dr. Harlan Caldwell). GroEL was detected by monoclonal mouse antibody that detects antigens present on all three GroEL paralogs (MA3-023, Invitrogen, ThermoFisher Scientific). Primary antibody incubation was allowed to proceed overnight at $4^{\circ} \mathrm{C}$ with rocking. Primary antibody solution was then washed out $3 x$ with TBS-T and TBS-T + 5\% NFDM + 1:2000 Dako goat anti-rabbit or anti-mouse HRP-conjugated immunoglobulins (Agilent, Santa Clara, CA, USA) was added. Secondary antibody incubation was allowed to proceed for at least 1 hour at $\mathrm{RT}^{\circ} \mathrm{C}$ with rocking. Secondary antibody solution was then washed out $3 \mathrm{x}$ with TBS-T and the membrane was exposed to Immobilon Western Chemiluminescent HRP Substrate (EMD Millipore Sigma) for $\sim 60 \mathrm{~s}$ prior to imaging on a Bio-Rad ChemiDoc XRS+ using detection settings appropriate for the band intensity of each analyte.

Chlamydial transformation. Transformation of plasmidless $C$. trachomatis serovar L2 was performed essentially as previously described ${ }^{46}$. In brief, $2 \mu \mathrm{g}$ of demethylated plasmid was used to transform $10^{6} \mathrm{EBs}$ in Tris $/ \mathrm{CaCl}_{2}$ buffer ( $10 \mathrm{mM}$ Tris, $50 \mathrm{mM} \mathrm{CaCl}$, $\mathrm{pH} \mathrm{7.4)} \mathrm{for} 30 \mathrm{~min}$ at $\mathrm{RT}^{\circ} \mathrm{C}$. The transformation inoculum was then used to infect a confluent monolayer of McCoy B mouse fibroblasts by centrifugation at $400 \times \mathrm{xg}$ for $15 \mathrm{~min}$ followed by incubation at $37^{\circ} \mathrm{C}$ for $15 \mathrm{~min}$. The inoculum was then aspirated, and complete DMEM was added to the well. At 8 $\mathrm{hpi}$, the medium was replaced with DMEM containing $1 \mathrm{unit} / \mathrm{mL}$ penicillin $\mathrm{G}$. Infected cells were passaged at $48 \mathrm{hpi}$ and 48 hours thereafter until penicillinresistant bacteria were isolated. Transformants were then expanded and infectious progeny purified by density-gradient centrifugation. Plasmid DNA was isolated from infected cells and transformed into chemically competent $E$. coli for plasmid isolation and subsequent sequencing to verify each transformant.

Analysis of YtgCR-FLAG expression. Induction of YtgCR-FLAG expression was performed by the addition of $20 \mathrm{nM}$ anhydrotetracycline (aTc; prepared as $20 \mu \mathrm{M}$ stock solution in sterile-filtered $\mathrm{diH}_{2} \mathrm{O}$ ) and allowed to proceed for the indicated times. Immunofluorescent confocal micrographs of YtgCR-FLAG expression from C. trachomatis L2 transformants were acquired on a Zeiss LSM800 Airyscan pointscanning confocal microscope using identical exposure and laser power setting between samples and conditions on a $40 \mathrm{X}$ oil objective. All immunostaining was performed using the protocol described above for the indicated antigens herein. Fields were chosen based on the reference GroEL-488 channel (detected with the same antibody as described above). FLAG expression was detected using a monoclonal rabbit anti-FLAG antibody (Cell Signaling Technology, \#14793S) and a goat anti-rabbit AlexaFluor-594 secondary antibody (Thermo Fisher Scientific). Zstacks spanning the entire depth of the inclusions in the field were acquired in 0.3 $\mu \mathrm{m}$ slices. Summed Z-projections were then produced from the Z-stacks in Fiji ImageJ. From the GroEL-488 channel, a threshold mask was created using the Triangle method and default settings. The Analyze Particles tool was then used to define regions of interest (ROI) with a minimum size of $30 \mu \mathrm{m}$. This necessarily excluded some inclusions that lacked contiguous or robust GroEL staining. Thereby, inclusion selection was randomized. The ROIs were then applied to the FLAG-594 channel and the Measure tool was used to analyze mean fluorescent intensity per pixel from the defined regions. Five fields in total were measured for each condition per replicate (total of 15 fields). From these measurements, three values were selected randomly per field ( 45 measurements total) and further analyzed for statistically distinguishable differences.

Expression of YtgCR in E. coli. Chemically competent BL21 (DE3) E. coli (Sigma Aldrich) were transformed with $\mathrm{pET151-EV,} \mathrm{-YtgCR}{ }^{w w w}-3 \times F L A G$ or $-\mathrm{YtgCR}^{\mathrm{YYF}}$ $3 \times F L A G$ and selected on lysogeny broth (LB) agar plates containing $50 \mu \mathrm{g} / \mathrm{mL}$ carbenicillin (Carb). Resistant colonies were selected and cultured overnight in LB $+50 \mu \mathrm{g} / \mathrm{mL}$ Carb. The following morning, optical density was measured at $600 \mathrm{~nm}$ $\left(\mathrm{OD}_{600}\right)$ and transformants were subcultured at $0.4 \mathrm{OD}_{600}$ units into $\mathrm{M} 9$ minimal medium (prepared from 5X M9 Minimal Salts [Sigma Aldrich]) supplemented with $2 \mathrm{mM} \mathrm{MgSO}_{4}, 100 \mu \mathrm{M} \mathrm{CaCl} 2,0.2 \%$ D-glucose and $50 \mu \mathrm{g} / \mathrm{mL}$ Carb. Cultures were incubated at $37^{\circ} \mathrm{C}$ with $300 \mathrm{RPM}$ shaking for 2 hours prior to addition of $500 \mu \mathrm{M}$ isopropyl $\beta$-d-1-thiogalactopyranoside (IPTG) with either vehicle (DMSO), indolmycin, or AN3365. Indolmycin was prepared at $1.0 \mathrm{mg} / \mathrm{mL}$ in DMSO and used at a working concentration of $1.0 \mu \mathrm{g} / \mathrm{mL}$. AN3365 (Cayman Chemical; CAS: 1234563-16-6) was prepared at $1.0 \mathrm{mg} / \mathrm{mL}$ in DMSO and used at a working concentration of $10 \mu \mathrm{g} / \mathrm{mL}$. Incubation proceeded for another two hours prior to measurement of final $\mathrm{OD}_{600}$ and collection of cell pellets for lysate preparation. Lysates were prepared by resuspending the bacterial cell pellet in $150 \mu \mathrm{L}$ Complete Bacterial Protein Extraction Reagent (B-PER; Thermo Fisher Scientific) supplemented with cOmplete, Mini, EDTA-free protease inhibitor cocktail (Roche). Lysates were incubated at $\mathrm{RT}^{\circ} \mathrm{C}$ for 15 minutes prior to the addition of 1X SDS-Laemmli buffer and boiling at $95^{\circ} \mathrm{C}$ for 10 minutes. Cell debris was pelleted by centrifugation and samples were processed for immunoblotting as described above using equivalent $O D$ amounts for each sample. FLAG expression was detected using a monoclonal mouse anti-FLAG antibody (Cell Signaling Technology, Danvers, MA, USA; \#8146S). Quantification of band intensity was performed using Fiji ImageJ.

5'-Rapid Amplification of cDNA Ends (5'-RACE). 5'-RACE was performed essentially as described previously ${ }^{22}$. In brief, $250 \mathrm{ng}$ of RNA isolated from each condition was converted into CDNA and processed through the SMARTer ${ }^{\oplus} 5^{\prime} / 3^{\prime}$ RACE Kit (Takara Bio) for $5^{\prime}$-RACE following manufacturer protocols. Half reaction volumes were used at each step. Gene-specific primers designed to amplify in the 3'-to-5' direction from within the $\operatorname{trp} B$ ORF were used for the primary RACE amplification and then a nested primer was used for the secondary RACE amplification to generate specific RACE products (see Supplementary Table 1 for a complete list of primers used in this study). RACE products were electrophoresed on a $2 \%$ agarose gel and visualized on a Bio-Rad ChemiDoc XRS+ gel imager. RACE products were then gel extracted using the NucleoSpin ${ }^{\circledR}$ Gel and PCR Clean-Up kit following manufacturer protocols. Gel extracted RACE products were cloned into the manufacturer-supplied pRACE sequencing vector using the 
bioRxiv preprint doi: https://doi.org/10.1101/2020.05.03.075317; this version posted May 3, 2020. The copyright holder for this preprint (which was not certified by peer review) is the author/funder, who has granted bioRxiv a license to display the preprint in perpetuity. It is made available under aCC-BY-NC-ND 4.0 International license.

In-Fusion ${ }^{\circledR}$ homology-directed (HD) Cloning Plus kit following manufacturer protocols. In-Fusion cloning reactions were then transformed directly into Stellar ${ }^{\mathrm{TM}}$ chemically competent $E$. coli and selected for on LB agar plates containing $50 \mu \mathrm{g} / \mathrm{mL}$ carbenicillin. Colonies were then screened for inserts using M13 forward and reverse primers to amplify the insert region in its entirety. Colony PCRs were performed using the high-fidelity Platinum ${ }^{\text {TM }}$ SuperFi' ${ }^{\text {TM }}$ DNA polymerase (Invitrogen, Thermo Fisher Scientific). PCR products were then isolated using the NucleoSpin ${ }^{\circledR}$ Gel and PCR Clean-Up kit. Isolated PCR products were sent for third-party sequencing at Eurofins Genomics (Louisville, KY, USA) with the M13 Forward primer to sequence into the gene-specific end. Sequencing results were then BLASTed against the $C$. trachomatis L2 434/Bu genome (NCBI Accession: NC 010287.1) and the 5'-most nucleotide was recorded and plotted as a density plot. For the 24 Bpd condition and the 24 Trp- $P_{\text {trpR }}$ samples, all sequences aligned to the same 5 ' nucleotide position, therefore two "FALSE" data points were added flanking each side of the reported value (e.g. 512,004 and 512,006 for $24 \mathrm{Bpd}$ ) to create a density around the reported nucleotide position. Sequencing data can be found in Supplementary Data 2. BLAST results are reported in Supplementary Data 3. Source data and source code can be found in Supplementary Data 4 and Supplementary Note 1, respectively.

Cloning. Ligation independent cloning of pBOMBL-YtgCR vectors was performed by amplifying the YtgCR ORF from the $C$. trachomatis L2 434/Bu chromosome (WWW) or from another vector harboring the YYF variant, with a C-terminally appended FLAG sequence and 5' Kpnl and 3' Eagl restriction enzyme sites (See Supplementary Table 1 for complete list of primers used in this study). The PCR product was inserted into a $\mathrm{pBOMB}$ derivative, pBOMBL, using the HiFi DNA Assembly Kit (New England Biolabs, Ipswich, MA, USA). pBOMBL contains a modified ribosome binding site to reduce leaky expression. The complete characterization of this plasmid will be described in a forthcoming manuscript. Cloning of the pET151-YtgCR-3xFLAG vectors was performed following manufacturer protocols for TOPO directional cloning into the pET151-D/TOPO base vector (Invitrogen, Thermo Fisher Scientific). The YtgCR sequence was amplified from $C$. trachomatis L2 gDNA with the reverse primer appending the 3xFLAG epitope through sequential amplifications since the entire sequence was not easily appended from one primer. The WWW motif was then mutated to YYF by base pair substitutions in the 5'-TGGTGGTGG-3' sequence, converting it to $5^{\prime}$ TACTACTTC-3'. These sequences were cloned into another vector and then subcloned into the $\mathrm{PET} 151$ vector by adding the requisite CACC sequence to the 5 ' end of the YtgCR ORF. All plasmids were sequence verified for proper insertion. Plasmids used in this study are described in Supplementary Table 2.

Sequence analysis of WWW motifs. All sequences from indicated chlamydial species were procured from the NCBI genome database, primarily by BLAST searches against the $C$. trachomatis L2 434/Bu CTL0174 or CTL0325 amino acid sequence. The .fasta file containing all sequences used can be found in Supplementary Data 5. A multiple sequence alignment (MSA) of the YtgCR sequences was generated using the MUSCLE algorithm ${ }^{57}$ in the MEGA7 software ${ }^{58}$. The MSA was graphically visualized in Jalview ${ }^{59}$. The full sequence alignments for CTL0174 and CTL0325 can be found in Supplementary Data 6 and 7 , respectively.

In silico analysis of putative TrpL sequences. We analyzed the genomes of 16 bacterial species (acquired from the NCBI genome database) predicted to contain $\operatorname{TrpL}$ attenuators ${ }^{51}$ for the purpose of comparison with the annotated TrpL in $C$. trachomatis (Supplementary Data 1). To identify attenuators, the intergenic region upstream of the trp operon where TrpL was predicted was manually surveyed for possible small upstream ORFs (UORF) containing tryptophan codons. Candidate uORFs had to meet the following criteria: 1.) contain an ATG start codon, 2.) contain tryptophan codons and 3.) contain an A/G-rich ( $\geq 50 \%)$ putative ribosome binding site (RBS) 4-14 bases upstream of the start codon. For some species, no candidate TrpL peptide or RBS could be identified. In the case of Deinococcus radiodurans, a candidate TrpL peptide was not identified where it had previously been predicted, though we note the possibility of a candidate $\operatorname{TrpL}$ found at a distal trp operon.

Analysis of $\boldsymbol{C}$. trachomatis $\mathbf{L} 2$ TrpL using PASIFIC. The intergenic region upstream of the trpBA ORFs in $C$. trachomatis, along with the intergenic region upstream of the E. coli K12 (NCBI Accession: NC 000913.3) trpEDCBA and tnaAB operons were input to the PASIFIC server (http://www.weizmann.ac.il/molgen/Sorek/PASIFIC/) for analysis using the default settings with the "I do not know the 3' ends of the transcripts" option selected. The summary of results can be found in
Supplementary Data 8, with the sequences used for analysis included in Supplementary Data 9

Graphs and statistical analysis. All plots were made in the ggplot2 base package ${ }^{60}$ and the ggpubr package (https://CRAN.R-project.org/package=ggpubr) in R Studio. All source code for each figure can be found in Supplementary Note 1. Source data for each plot can be found in Supplementary Data 4. Statistics were computed in R and specific tests are described in the figure legends. Source code for the statistical analyses is included with the source code for each figure.

\section{Data availability}

Any data that support the findings of this study beyond what is included in the Supplementary Information are available from the corresponding author upon request. Supplementary figures, tables, data and notes are included in the Supplementary Information.

\section{References}

1. Ibana, J. A. et al. Inhibition of indoleamine 2,3-dioxygenase activity by levo-1-methyl tryptophan blocks gamma interferon-induced chlamydia trachomatis persistence in human epithelial cells. Infect. Immun. 79, 4425-4437 (2011).

2. Macchiarulo, A., Camaioni, E., Nuti, R. \& Pellicciari, R. Highlights at the gate of tryptophan catabolism : a review on the mechanisms of activation and regulation of indoleamine 2,3-dioxygenase (IDO), a novel target in cancer disease. Amino Acids 37, 219-229 (2009).

3. Zhang, Y. J. et al. Tryptophan biosynthesis protects mycobacteria from CD4 T-Cell-mediated Killing. Cell 155, 1296-1308 (2013).

4. Chu, P., Rodriguez, A. R., Arulanandam, B. P. \& Klose, K. E. Tryptophan prototrophy contributes to Francisella tularensis evasion of gamma interferon-mediated host defense. Infect. Immun. 79, 2356-2361 (2011).

5. David Sibley, L., Messina, M. \& Niesman, I. R. Stable DNA transformation in the obligate intracellular parasite Toxoplasma gondii by complementation of tryptophan auxotrophy. Proc. Natl. Acad. Sci. U. S. A. 91, 5508-5512 (1994).

6. Steiger, R. F. \& Steiger, E. Cultivation of Leishmania donovani and Leishmania braziliensis in Defined Media: Nutritional Requirements. J. Protozool. 24, 437-441 (1977).

7. Pantoja, L. G., Miller, R. D., Ramirez, J. a., Molestina, R. E. \& Summersgill, J. T. Characterization of Chlamydia pneumoniae persistence in HEp-2 cells treated with gamma interferon. Infect. Immun. 69, 7927-7932 (2001).

8. Beatty, W. L., Belanger, T. A., Desai, A. A., Morrison, R. P. \& Byrne, G. I. Tryptophan depletion as a mechanism of gamma interferon-mediated chlamydial persistence. Infect. Immun. 62, 3705-3711 (1994).

9. Gunsalus, R. P. \& Yanofsky, C. Nucleotide sequence and expression of Escherichia coli trpR, the structural gene for the trp aporepressor. Proc. Natl. Acad. Sci. 77, 7117-7121 (2006).

10. Zurawski, G., Elseviers, D., Stauffer, G. V. \& Yanofsky, C. Translational control of transcription termination at the attenuator of the Escherichia coli tryptophan operon. Proc. Natl. Acad. Sci. U. S. A. 75, 5988-5992 (1978)

11. Joachimiak, A., Kelley, R. L., Gunsalus, R. P., Yanofsky, C. \& Sigler, P. B. Purification and characterization of trp aporepressor. Proc. Natl. Acad. Sci. U. S. A. 80, 668-672 (1983).

12. Yanofsky, C., Kelley, R. L. \& Horn, V. Repression is relieved before attenuation in the trp operon of Escherichia coli as tryptophan starvation becomes increasingly severe. J. Bacteriol. 158, 1018-1024 (1984).

13. Korn, L. J. \& Yanofsky, C. Polarity suppressors defective in transcription termination at the attenuator of the tryptophan operon of Escherichia coli have altered rho factor. J. Mol. Biol. 106, 231-241 (1976).

14. Fuller, R. S. \& Platt, T. The attenuator of the tryptophan operon in E. coli: rho-mediated release of RNA polymerase from a transcription termination complex in vitro. Nucleic Acids Res. 5, 4613-4623 (1978).

15. Stephens, R. S. et al. Genome sequence of an obligate intracellular pathogen of humans: Chlamydia trachomatis. Science (80-. ). 282, 754759 (1998) 
bioRxiv preprint doi: https://doi.org/10.1101/2020.05.03.075317; this version posted May 3, 2020. The copyright holder for this preprint (which was not certified by peer review) is the author/funder, who has granted bioRxiv a license to display the preprint in perpetuity. It is made available under aCC-BY-NC-ND 4.0 International license.

16.

Wood, H. et al. Regulation of tryptophan synthase gene expression in Chlamydia trachomatis. Mol. Microbiol. 49, 1347-1359 (2003).

17. Fehlner-Gardiner, C. et al. Molecular Basis Defining Human Chlamydia trachomatis Tissue Tropism. J. Biol. Chem. 277, 26893-26903 (2002).

18. Mueller, K. E., Wolf, K. \& Fields, K. A. Gene Deletion by FluorescenceReported Allelic Exchange Mutagenesis in Chlamydia trachomatis. MBio 7, 1-9 (2016).

19. Carlson, J. H., Wood, H., Roshick, C., Caldwell, H. D. \& McClarty, G. In vivo and in vitro studies of Chlamydia trachomatis TrpR:DNA interactions. Mol. Microbiol. 59, 1678-1691 (2006).

20. Akers, J. C. \& Tan, M. Molecular mechanism of tryptophan-dependent transcriptional regulation in Chlamydia trachomatis. J. Bacteriol. 188, 4236-4243 (2006).

21. Brinkworth, A. J., Wildung, M. R. \& Carabeo, R. A. Genomewide Transcriptional Responses of Iron-Starved Chlamydia trachomatis Reveal Prioritization of Metabolic Precursor Synthesis over Protein Translation. mSystems 3, e00184-17 (2018).

22. Pokorzynski, N. D., Brinkworth, A. J. \& Carabeo, R. A bipartite irondependent transcriptional regulation of the tryptophan salvage pathway in Chlamydia trachomatis. Elife 8, 1-32 (2019).

23. Ouellette, S. P. \& Carabeo, R. A. A functional slow recycling pathway of transferrin is required for growth of Chlamydia. Front. Microbiol. 1, 112 (2010)

24. Faris, R. et al. Chlamydia trachomatis CT229 Subverts Rab GTPaseDependent CCV Trafficking Pathways to Promote Chlamydial Infection. Cell Rep. 26, 3380-3390.e5 (2019).

25. Pokorzynski, N. D., Thompson, C. C. \& Carabeo, R. A. Ironing Out the Unconventional Mechanisms of Iron Acquisition and Gene Regulation in Chlamydia. Front. Cell. Infect. Microbiol. 7, 1-19 (2017).

26. Lloyd, J. M., O'Dowd, T., Driver, M. \& Tee, D. E. Demonstration of an epitope of the transferrin receptor in human cervical epithelium--a potentially useful cell marker. J. Clin. Pathol. 37, 131-135 (1984).

27. Filardo, S. et al. Selected Immunological Mediators and Cervical Microbial Signatures in Women with Chlamydia trachomatis Infection . mSystems 4, 1-14 (2019).

28. Valenti, P. et al. Role of Lactobacilli and Lactoferrin in the Mucosal Cervicovaginal Defense. Front. Immunol. 9, 1-14 (2018).

29. Sessa, R. et al. Lactobacilli-lactoferrin interplay in Chlamydia trachomatis infection. Pathog. Dis. 75, 1-9 (2017).

30. Ziklo, N., Huston, W. M., Hocking, J. S. \& Timms, P. Chlamydia trachomatis Genital Tract Infections: When Host Immune Response and the Microbiome Collide. Trends Microbiol. 24, 750-765 (2016).

31. Akers, J. C., HoDac, H., Lathrop, R. H. \& Tan, M. Identification and functional analysis of CT069 as a novel transcriptional regulator in Chlamydia. J. Bacteriol. 193, 6123-6131 (2011).

32. Thompson, C. C., Nicod, S. S., Malcolm, D. S., Grieshaber, S. S. \& Carabeo, R. A. Cleavage of a putative metal permease in Chlamydia trachomatis yields an iron-dependent transcriptional repressor. Proc. Natl. Acad. Sci. U. S. A. 109, 10546-51 (2012).

33. Thompson, C. C. \& Carabeo, R. A. An optimal method of iron starvation of the obligate intracellular pathogen, Chlamydia trachomatis. Front. Microbiol. 2, (2011).

34. Wyrick, P. B. Chlamydia trachomatis Persistence In Vitro: An Overview. J. Infect. Dis. 201, 88-95 (2010).

35. Panzetta, M. E., Valdivia, R. H. \& Saka, H. A. Chlamydia Persistence: A Survival Strategy to Evade Antimicrobial Effects in-vitro and in-vivo.

Front. Microbiol. 9, 1-11 (2018).

36. Belland, R. J. et al. Transcriptome analysis of chlamydial growth during IFN-gamma-mediated persistence and reactivation. Proc. Natl. Acad. Sci. U. S. A. 100, 15971-15976 (2003).

37. Dill, B. D., Dessus-Babus, S. \& Raulston, J. E. Identification of ironresponsive proteins expressed by Chlamydia trachomatis reticulate bodies during intracellular growth. Microbiology 155, 210-219 (2009). Williams, T. L., Yin, Y. W. \& Carter, C. W. Selective inhibition of bacterial tryptophanyl-tRNA synthetases by indolmycin is mechanismbased. J. Biol. Chem. 291, 255-265 (2016).

39. Werner, R. G., Thorpe, L. F., Reuter, W. \& Nierhaus, K. H. Indolmycin Inhibits Prokaryotic Tryptophanyl-tRNA Ligase. Eur. J. Biochem. 68, 1-3 (1976).

40. Gupta, P., Kannan, K., Mankin, A. S. \& Vázquez-Laslop, N. Regulation of gene expression by macrolide-induced ribosomal frameshifting. Mol. Cell 52, 629-642 (2013).
41. Rock, F. L. et al. An antifungal agent inhibits an aminoacyl-tRNA synthetase by trapping tRNA in the editing site. Science (80-. ). 316, 1759-1761 (2007).

42. Hernandez, V. et al. Discovery of a Novel Class of Boron-Based Antibacterials with Activity against Gram-Negative Bacteria. Antimicrob. Agents Chemother. 57, 1394-1403 (2013).

43. Ouellette, S. P., Rueden, K. J. \& Rucks, E. A. Tryptophan codondependent transcription in chlamydia pneumoniae during gamma interferon-mediated tryptophan limitation. Infect. Immun. 84, 27032713 (2016).

44. Ouellette, S. P. et al. Global transcriptional upregulation in the absence of increased translation in Chlamydia during IFNY-mediated host cell tryptophan starvation. Mol. Microbiol. 62, 1387-1401 (2006).

45. Hatch, N. D. \& Ouellette, S. P. Inhibition of tRNA Synthetases Induces Persistence in Chlamydia. Infect. Immun. 1-15 (2020). doi:10.1128/iai.00943-19

46. Ouellette, S. P., Messerli, P. R., Wood, N. A. \& Hajovsky, H. Characterization of chlamydial Rho and the role of Rho-mediated transcriptional polarity during interferon gamma-mediated tryptophan limitation. Infect. Immun. 86, 1-19 (2018).

47. Zwiefka, A., Kohn, H. \& Widger, W. R. Transcription Termination Factor rho: The Site of Bicyclomycin Inhibition in Escherichia coli. Biochemistry 32, 3564-3570 (1993).

48. Skordalakes, E., Brogan, A. P., Park, B. S., Kohn, H. \& Berger, J. M. Structural mechanism of inhibition of the Rho transcription termination factor by the antibiotic bicyclomycin. Structure 13, 99-109 (2005).

49. Gollnick, P., Ishino, S., Kuroda, M. I., Henner, D. J. \& Yanofsky, C. The mtr locus is a two-gene operon required for transcription attenuation in the trp operon of Bacillus subtilis. Proc. Natl. Acad. Sci. U. S. A. 87, 8726-30 (1990).

50. Merino, E. \& Yanofsky, C. Transcription attenuation: A highly conserved regulatory strategy used by bacteria. Trends Genet. 21, 260-264 (2005).

51. Merino, E., Jensen, R. A. \& Yanofsky, C. Evolution of bacterial trp operons and their regulation. Curr. Opin. Microbiol. 11, 78-86 (2008).

52. Millman, A., Dar, D., Shamir, M. \& Sorek, R. Computational prediction of regulatory, premature transcription termination in bacteria. Nucleic Acids Res. 45, 886-893 (2017).

53. Caldwell, H. D., Kromhout, J. \& Schachter, J. Purification and partial characterization of the major outer membrane protein of Chlamydia trachomatis. Infect. Immun. 31, 1161-1176 (1981).

54. Schindelin, J. et al. Fiji: An open-source platform for biological-image analysis. Nat. Methods 9, 676-682 (2012).

55. Kelley, L. A., Mezulis, S., Yates, C. M., Wass, M. N. \& Sternberg, M. J. E. The Phyre2 web portal for protein modeling, prediction and analysis. Nat. Protoc. 10, 845-858 (2015).

56. Pettersen, E. F. et al. UCSF Chimera - A visualization system for exploratory research and analysis. J. Comput. Chem. 25, 1605-1612 (2004).

57. Edgar, R. C. MUSCLE: Multiple sequence alignment with high accuracy and high throughput. Nucleic Acids Res. 32, 1792-1797 (2004).

58. Kumar, S., Stecher, G. \& Tamura, K. MEGA7: Molecular Evolutionary Genetics Analysis Version 7.0 for Bigger Datasets. Mol. Biol. Evol. 33, 1870-1874 (2016).

59. Waterhouse, A. M., Procter, J. B., Martin, D. M. A., Clamp, M. \& Barton, G. J. Jalview Version 2-A multiple sequence alignment editor and analysis workbench. Bioinformatics 25, 1189-1191 (2009).

60. Wickham, H. ggplot2: Elegant Graphics for Data Analysis. (SpringerVerlag New York, 2009).

\section{Acknowledgements}

The authors would like to acknowledge the Advanced Microscopy Core Facility staff at the University of Nebraska Medical Center for their excellent assistance in training and instrument maintenance. We would also like to acknowledge Dr. Rotem Sorek and Adi Millman (Weizmann Institute of Science, Israel) for their generous assistance in use of the PASIFIC tool. This study was supported by funding from the U.S. National Institutes of Health, National Institutes of Allergy and Infectious Disease grants R01 Al065545 (R.A.C.), R01 Al132406 (R.A.C. \& S.P.O.) and F31 Al136295 (N.D.P.). This work was also supported by funding from 
bioRxiv preprint doi: https://doi.org/10.1101/2020.05.03.075317; this version posted May 3, 2020. The copyright holder for this preprint (which was not certified by peer review) is the author/funder, who has granted bioRxiv a license to display the preprint in perpetuity. It is made available under aCC-BY-NC-ND 4.0 International license.

the U.S. National Science Foundation through grant 1810599 (S.P.O.). N.D.P. was further supported by the National Institutes of Health Protein Biotechnology Training Program at Washington State University (T32 GM008336) and a fellowship from the Seattle Chapter of Achievement Rewards for College Scientists (ARCS). The University of Nebraska Medical Center Advanced Microscopy Core Facility receives partial support from the National Institute for General Medical Science (NIGMS) INBRE - P20 GM103427 and COBRE - P30 GM106397 grants, as well as support from the National Cancer Institute (NCI) for The Fred \& Pamela Buffett Cancer Center Support Grant- P30 CA036727, and the Nebraska Research Initiative. This publication's contents and interpretations are the sole responsibility of the authors.

\section{Author contributions}

N.D.P. and R.A.C. designed the experiments and wrote the manuscript. N.D.P. performed the experiments, and N.D.P. and R.A.C. analyzed the data. N.D.H. and S.P.O. provided reagents and samples critical to the completion of the research, including samples used for generating the data presented in Fig. $4 \mathrm{~b}$ and the transformed chlamydial strains used in Fig. 2c-e. R.A.C. and S.P.O. both performed supervisory roles in the conception, direction and completion of the research.

\section{Competing interests}

The authors have no competing interests to declare. 
bioRxiv preprint doi: https://doi.org/10.1101/2020.05.03.075317; this version posted May 3, 2020. The copyright holder for this preprint (which was not certified by peer review) is the author/funder, who has granted bioRxiv a license to display the preprint in perpetuity. It is made available under aCC-BY-NC-ND 4.0 International license.

\section{Supplementary Information}
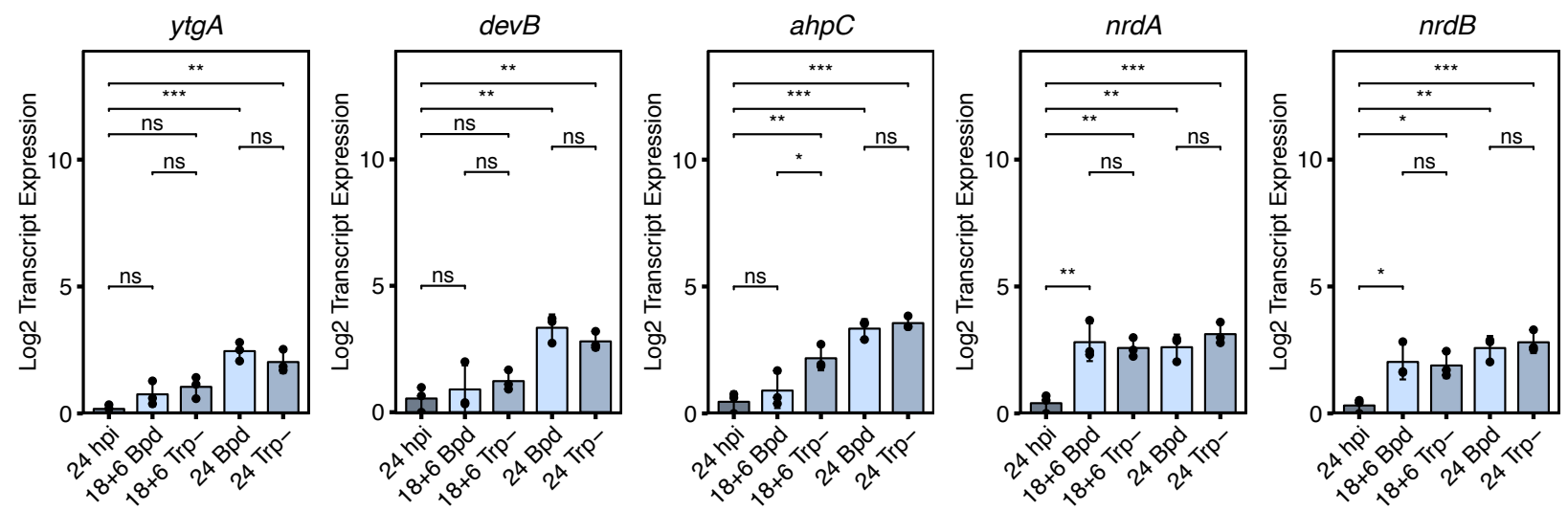

Supplementary Fig. 1 | Previously characterized iron-regulated genes converge at common expression endpoint in response to both iron-limited and tryptophan-starved persistence. Transcript expression of genes previously identified as iron-regulated in C. trachomatis serovar L2. RNA was isolated from infected HeLa cells (MOI 2) and transcript abundance was quantified by RT-qPCR after normalization to genome copy number. Note that ytgA is a known regulatory target of YtgR. Statistical significance was determined by one-way ANOVA followed by Tukey's post-hoc test of honest significant differences. ${ }^{*}=p<0.05,{ }^{* *}=p<0.01,{ }^{* * *}=p<0.001$. 
bioRxiv preprint doi: https://doi.org/10.1101/2020.05.03.075317; this version posted May 3, 2020. The copyright holder for this preprint (which was not certified by peer review) is the author/funder, who has granted bioRxiv a license to display the preprint in perpetuity. It is made available under aCC-BY-NC-ND 4.0 International license.

a
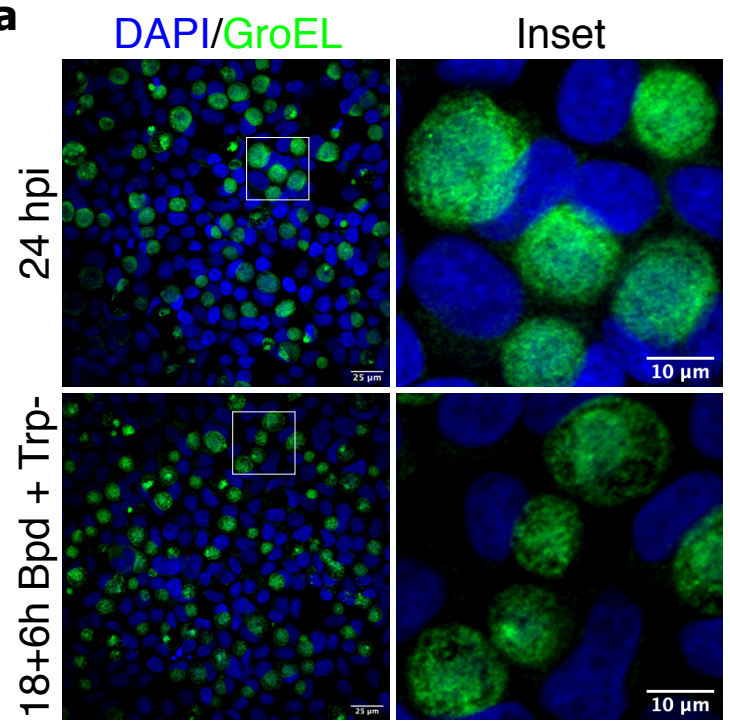

b

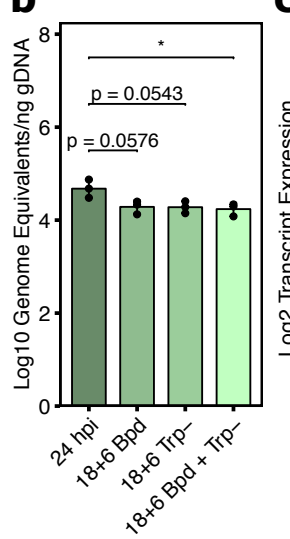

C

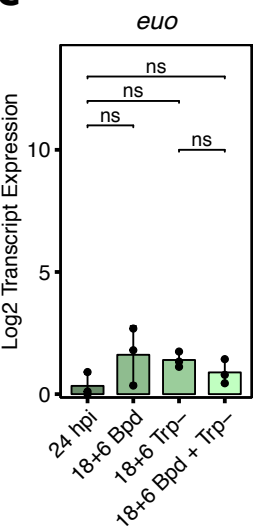

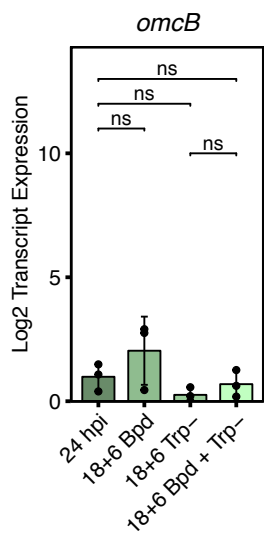

Supplementary Fig. 2 | Combined stress of iron and tryptophan limitation does not further induce persistence in C. trachomatis. a, Representative immunofluorescent confocal micrographs of $C$. trachomatis L2-infected HeLa cells indicating inclusion morphology following the combination of iron and tryptophan limitation for $6 \mathrm{~h}$. Note that inclusions are very similar to those observed following $6 \mathrm{~h}$ tryptophan limitation in Fig 1a. b, C. trachomatis L2 genome copy number quantified as in Fig. 1b for the combined stress condition. c, Transcript expression of persistence biomarkers euo and omcB following combined stress treatment. Statistical significance was determined by one-way ANOVA followed by Tukey's post-hoc test of honest significant differences. ${ }^{*}=p<0.05,{ }^{* *}=p<0.01,{ }^{* *}=p<0.001$. 
a
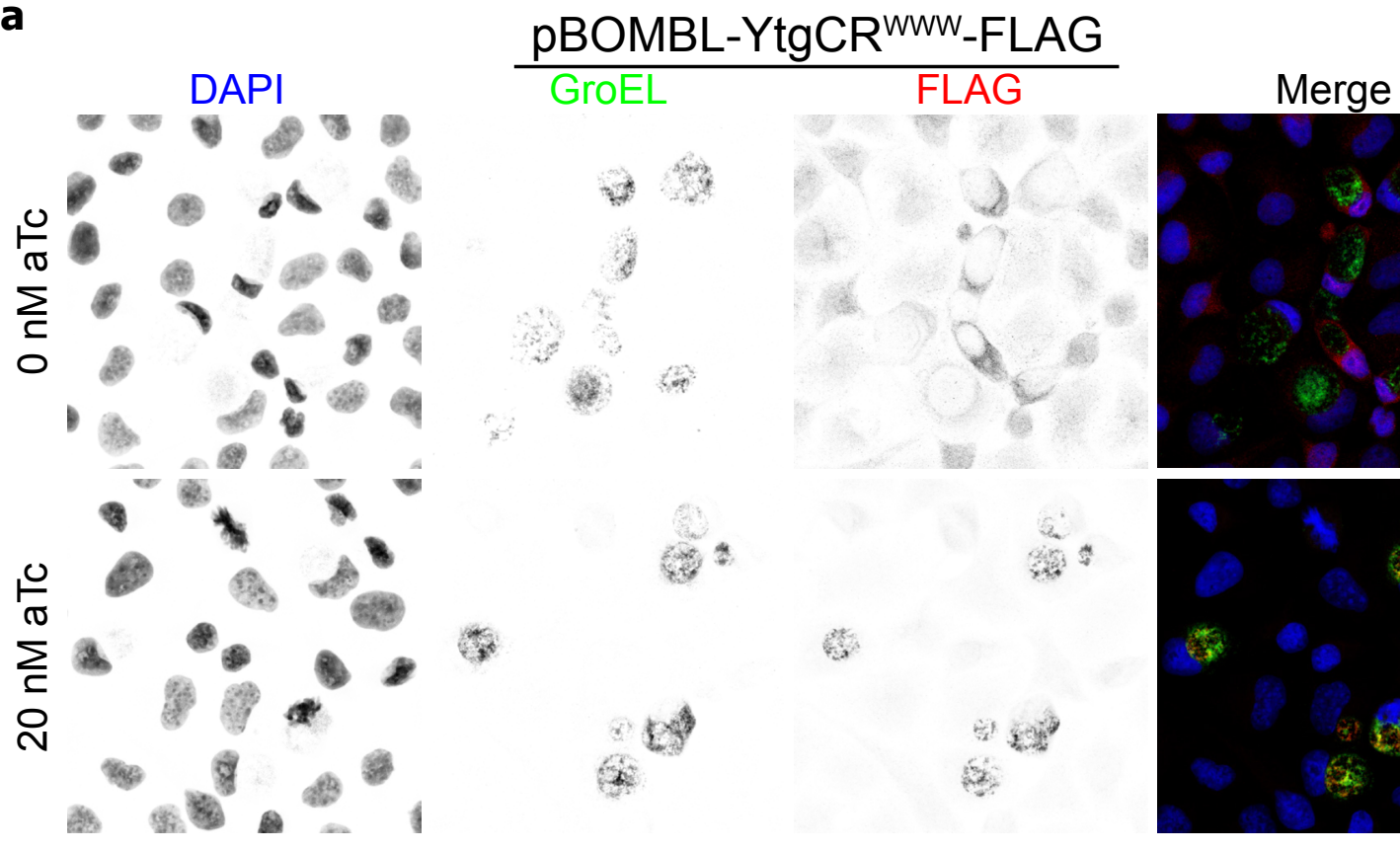

b
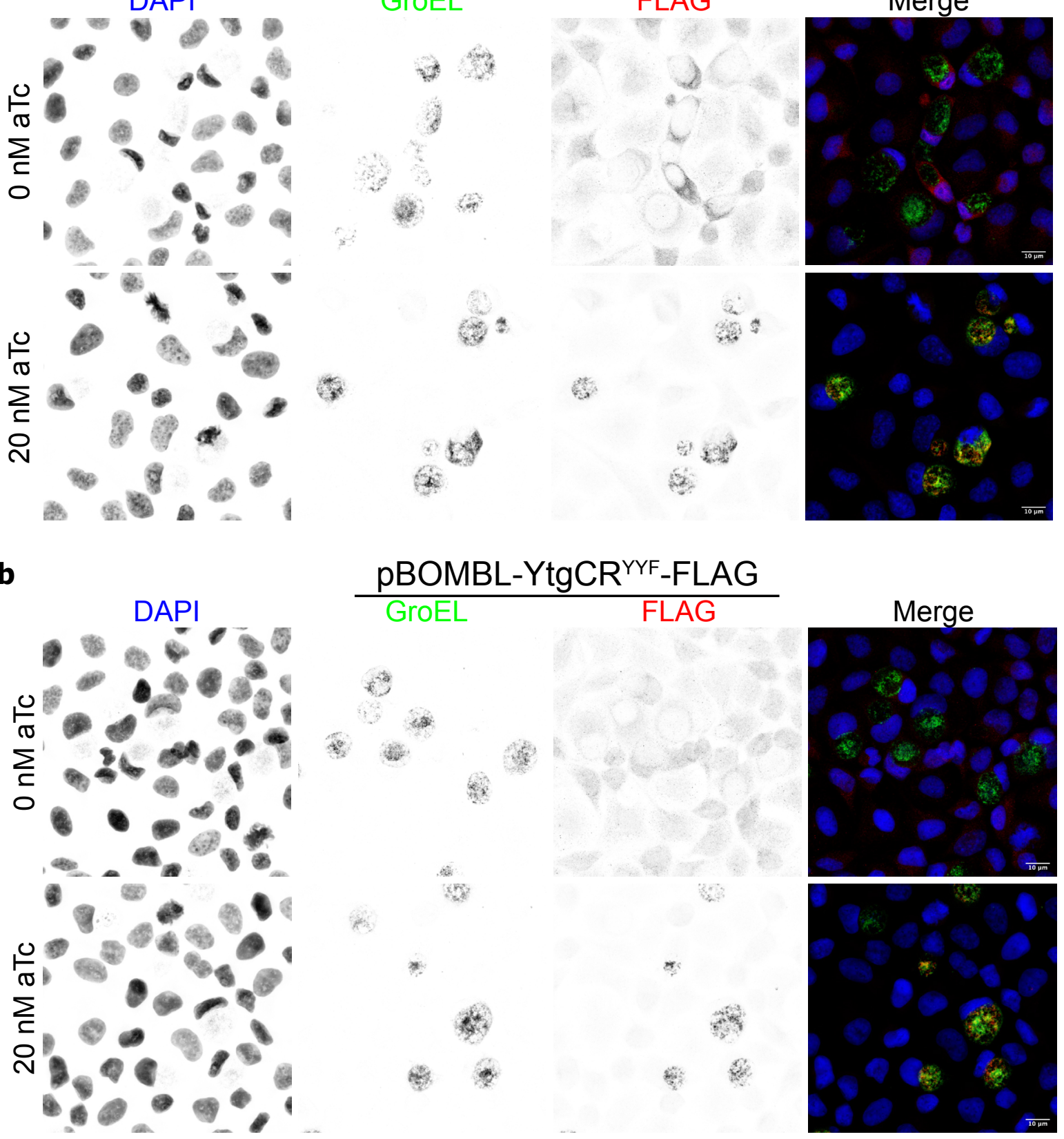

Supplementary Fig. 3 | C. trachomatis L2 pBOMBL-YtgCR-FLAG transformants specifically express YtgCR-FLAG in the presence of anhydrotetracycline. a, Represenative immunofluorescent confocal micrographs of McCoy B mouse fibroblasts infected with the WWW (wildtype) variant of the $\mathrm{pBOMBL}-Y \operatorname{tgCR}-\mathrm{FLAG}$ construct (MOI 5) and treated with $20 \mathrm{nM}$ anhydrotetracyline (aTc) for $6 \mathrm{~h}$ to induce YtgCR-FLAG expression. Monoclonal mouse antibody against the GroEL_1 - GroEL_3 antigens was used a counterstain for $C$. trachomatis. $\mathbf{b}$, Same as in a for the YYF variant of the transformant. 
bioRxiv preprint doi: https://doi.org/10.1101/2020.05.03.075317; this version posted May 3, 2020. The copyright holder for this preprint (which was not certified by peer review) is the author/funder, who has granted bioRxiv a license to display the preprint in perpetuity. It is made available under aCC-BY-NC-ND 4.0 International license.

a

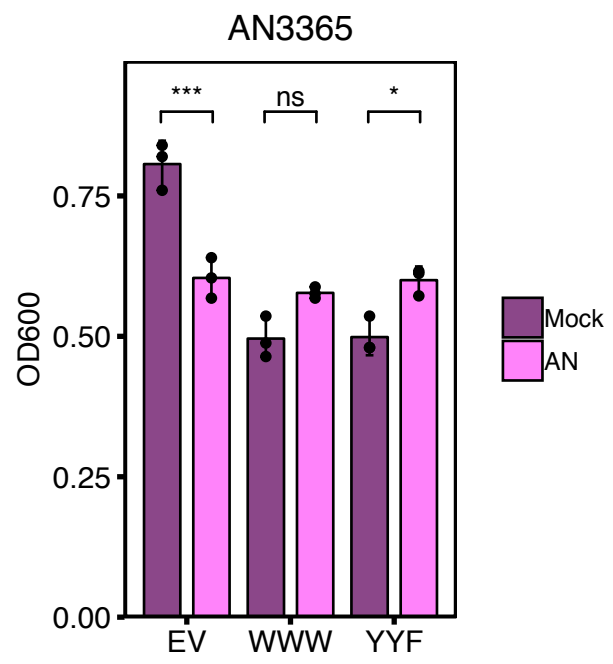

b

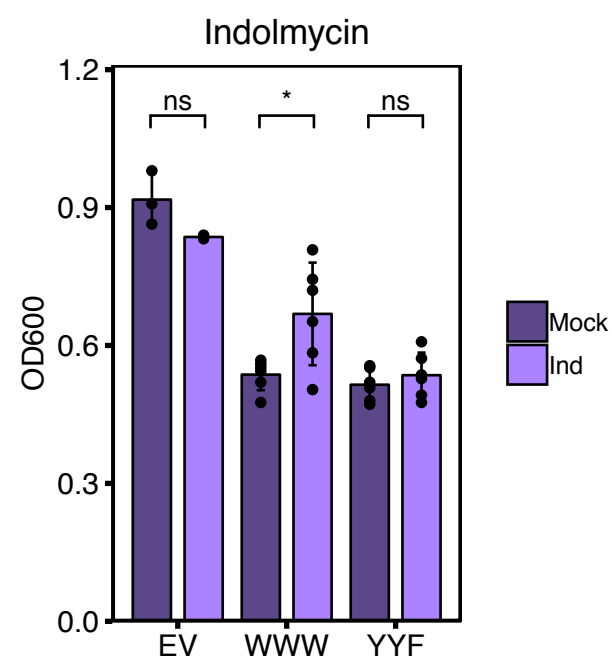

Supplementary Fig. 4 | Inhibition of YtgCR-3xFLAG expression by addition of AN3365 or indolmycin rescues E. coli growth. a, Optical density measured at $600 \mathrm{~nm}\left(\mathrm{OD}_{600}\right)$ from BL21 (DE3) E. coli cultures transformed with empty vector pET151 (EV), pET151-YtgCR ${ }^{W w W}-3 \times F L A G$ (WWW) or pET151-YtgCR ${ }^{Y Y F}-3 x F L A G$ (YYF) following treatment with either $10 \mu \mathrm{g} / \mathrm{mL}$ AN3365 (AN) or mock treatment. OD 600 was measured at the end of each experiment. Note that AN3365 treatment alone significantly inhibited $E$. coli growth and that inhibition of YtgCR expression rescued growth back to EV levels in the presence of AN3365. b. Same as in a for indolmycin (Ind)-treated experiments. Note here that indolmycin treatment alone does not affect $E$. coli growth. Statistical significance was determined by a Two-way factorial ANOVA followed by Tukey's post-hoc test for honestly significant differences. ${ }^{*}=p<0.05,{ }^{* *}=p<0.01,{ }^{* *}=p<0.001$. 
bioRxiv preprint doi: https://doi.org/10.1101/2020.05.03.075317; this version posted May 3, 2020. The copyright holder for this preprint (which was not certified by peer review) is the author/funder, who has granted bioRxiv a license to display the preprint in perpetuity. It is made available under aCC-BY-NC-ND 4.0 International license.
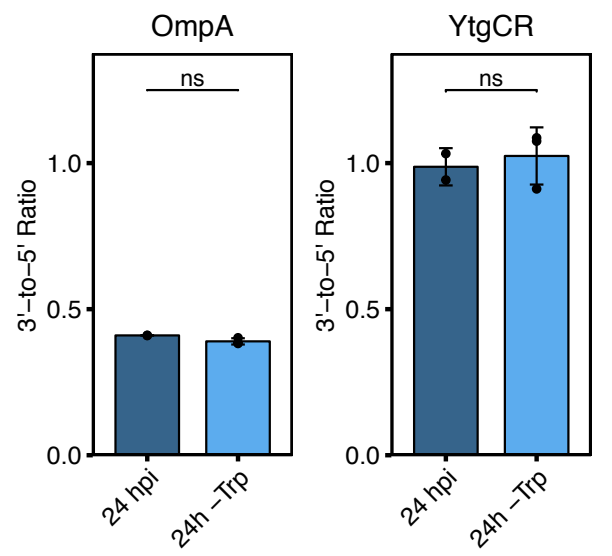

Supplementary Fig. 5 | Media-defined tryptophan limitation does not induce 3' transcriptional polarity of YtgCR. Analysis of 3'

transcriptional polarity determined by RT-qPCR. C. trachomatis L2-infected HeLa cells (MOI 2) were tryptophan starved by media replacement for $24 \mathrm{~h}$ at the start of infection. YtgCR transcriptional polarity was measured as in Fig. 4b and 4c. OmpA transcriptional polarity was included as a negative control since it did not polarize in response to $14 \mathrm{~h}$ indolmycin treatment (Fig. $4 \mathrm{~b}$ ). Statistical significance was determined by Welch's pairwise $t$-test for unequal variance. ${ }^{*}=p<0.05,{ }^{* *}=p<0.01,{ }^{* * *}=p<0.001$. 
bioRxiv preprint doi: https://doi.org/10.1101/2020.05.03.075317; this version posted May 3, 2020. The copyright holder for this preprint (which was not certified by peer review) is the author/funder, who has granted bioRxiv a license to display the preprint in perpetuity. It is made available under aCC-BY-NC-ND 4.0 International license.

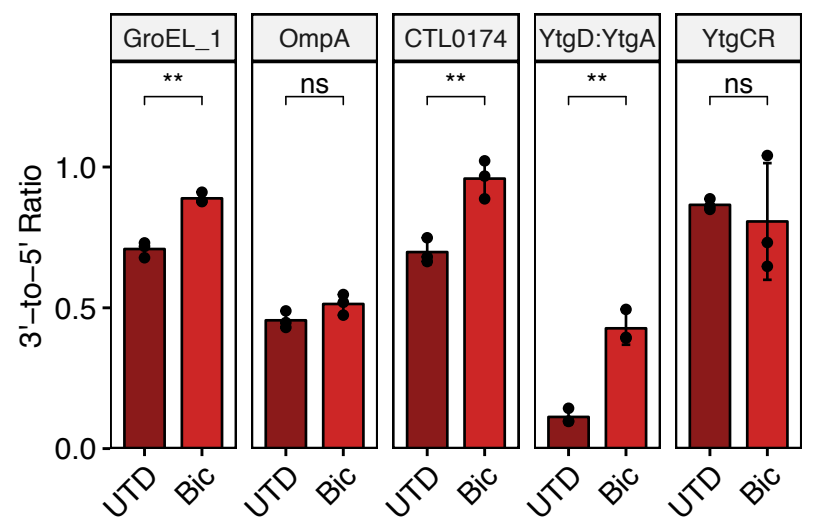

Supplementary Fig. 6 | 3' transcriptional polarity of YtgCR is not regulated by the transcription termination factor Rho. Analysis of 3' transcriptional polarity determined by RT-qPCR for genes assayed in Fig. 4b. C. trachomatis L2-infected HeLa cells (MOI 2) were untreated (UTD) or treated with $25 \mu \mathrm{g} / \mathrm{mL}$ of the Rho inhibitor bicyclomycin (Bic) for $6 \mathrm{~h}$ to assess Rho-dependence. Transcriptional polarity of the $y t g$ operon

(YtgD:YtgA) was included as a positive control for Rho-dependent regulation of transcription termination. Statistical significance was determined by Welch's pairwise $t$-test for unequal variance. ${ }^{*}=p<0.05,{ }^{* *}=p<0.01,{ }^{* *}=p<0.001$. 
bioRxiv preprint doi: https://doi.org/10.1101/2020.05.03.075317; this version posted May 3, 2020. The copyright holder for this preprint (which was not certified by peer review) is the author/funder, who has granted bioRxiv a license to display the preprint in perpetuity. It is made available under aCC-BY-NC-ND 4.0 International license.

\section{Terminator Fold}

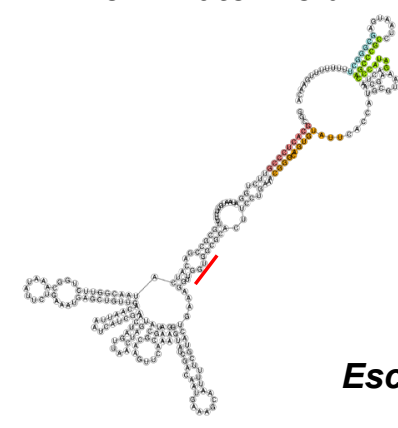

Anti-Terminator Fold

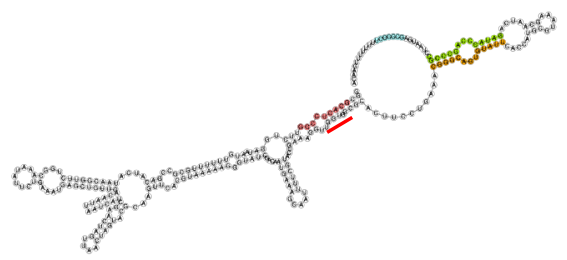

Escherichia coli K-12

trpL

Score: 0.63

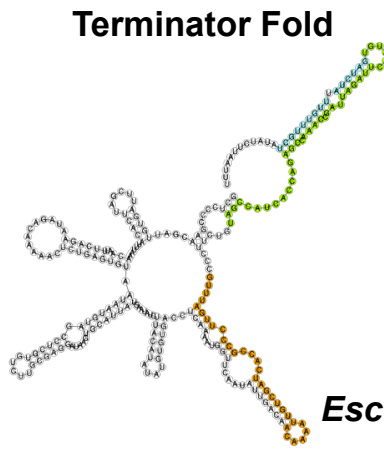

Anti-Terminator Fold

Terminator Fold

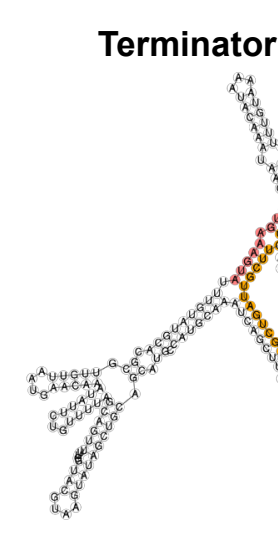<smiles>[AlH2][VH2]</smiles>

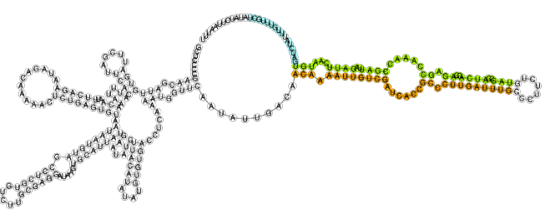

Escherichia coli K-12

tnaC

Score: $\mathbf{0 . 3 4}$

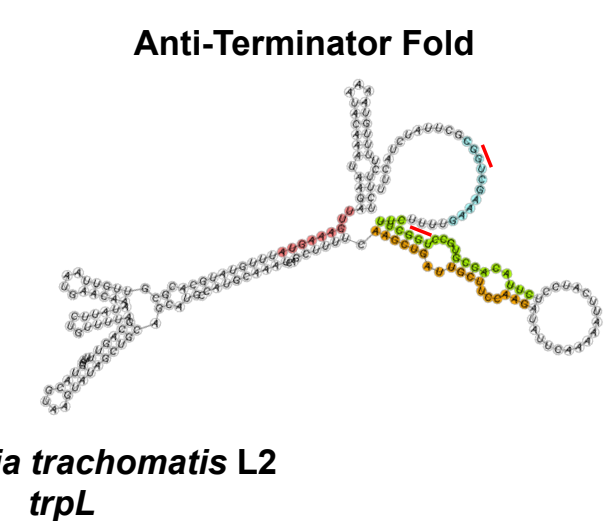

Chlamydia trach
trpL

Score: $\mathbf{0 . 3 7}$

Supplementary Fig. 7 | The trpRBA intergenic region is not predicted to form a cis-attenuator termination structure. The PASIFIC algorithm was used to predict attenuator function from three regions: the intergenic region upstream of the $E$. coli trpEDCBA operon containing the $\operatorname{trp} L$ leader peptide, the intergenic upstream of the $E$. coli tna $A B$ operon containing the thaC leader peptide and the intergenic region upstream of the $C$. trachomatis trpBA ORFs containing the putative trpL leader peptide. The $E$. coli trpL was used a positive control for attenuator function, whereas the tnaC leader sequence was used as a negative control as it does not rely on a terminator/anti-terminator formation for its regulatory function. The PASIFIC algorithm predicts regions of base pairing that could form putative terminators (blue and green base-pairing) and antiterminators (green and orange base-pairing) and computes a score for the prediction. A score of 0.50 or higher is considered reliable. Whereas the E. coli trpL leader sequence was identified as a strong positive attenuator sequence and reproduces base-pairing predicted in its original description, the thaC leader sequence is not predicted to form a terminator/anti-terminator structure. Likewise, the intergenic region of the $C$. trachomatis trpRBA operon is not predicted to form a functional terminator/anti-terminator structure. Notably, as the red lines indicate, the tryptophan codons in the putative $C$. trachomatis trp $L$ are predicted to be involved in the base pairing interaction of the terminator hairpin, precluding ribosomes from "sensing" these codons to form the terminator hairpin. This is consistent with the prediction of poor attenuator function. Note that this is not the case for the E. coli trpL leader sequence. Additionally, PASIFIC predicts the transcript termination site when one is not known. For this analysis, all predictions were determined using an unknown termination site. For $C$. trachomatis, termination is predicted to occur prior to the end of the putative trpL peptide coding sequence, suggesting that this region is possibly misannotated. See Methods for complete description of analysis. 
bioRxiv preprint doi: https://doi.org/10.1101/2020.05.03.075317; this version posted May 3, 2020. The copyright holder for this preprint (which was not certified by peer review) is the author/funder, who has granted bioRxiv a license to display the preprint in perpetuity. It is made available under aCC-BY-NC-ND 4.0 International license.

a

\section{YtgCR}

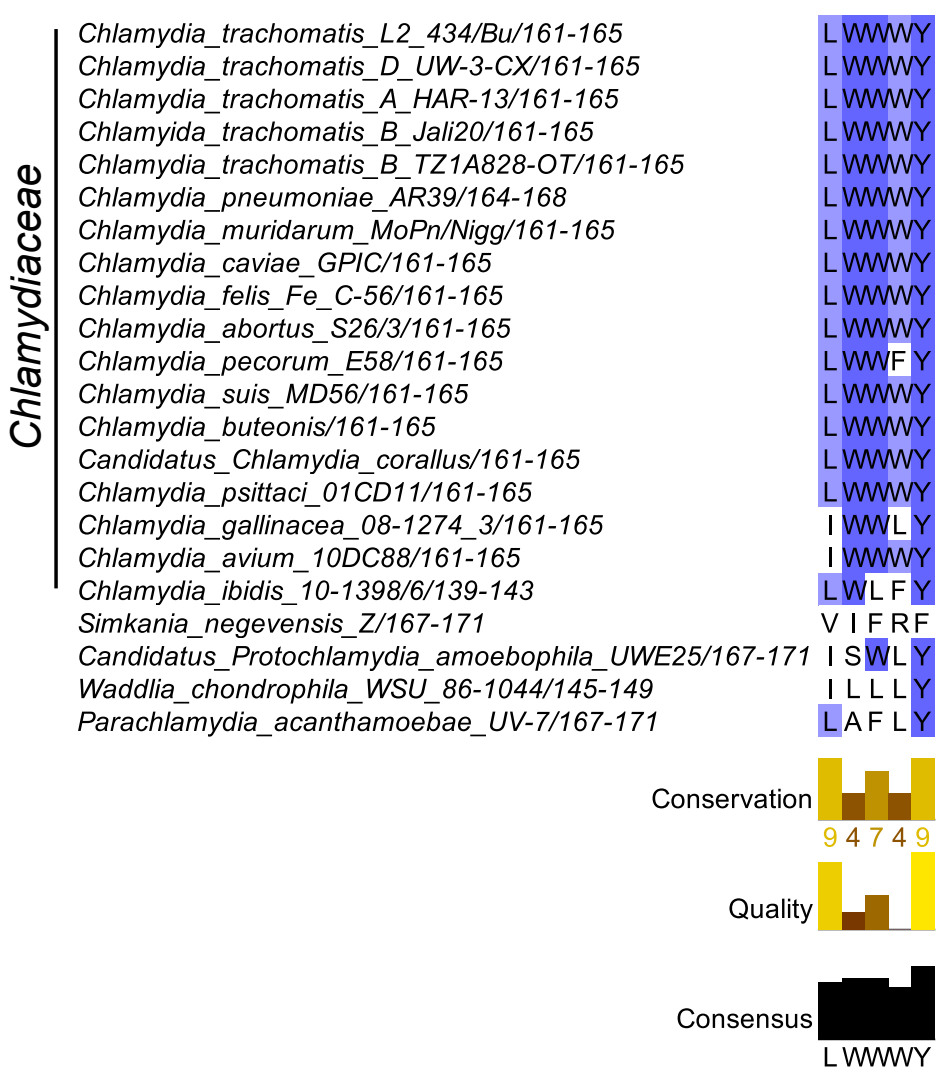

b

\section{CTL0174}

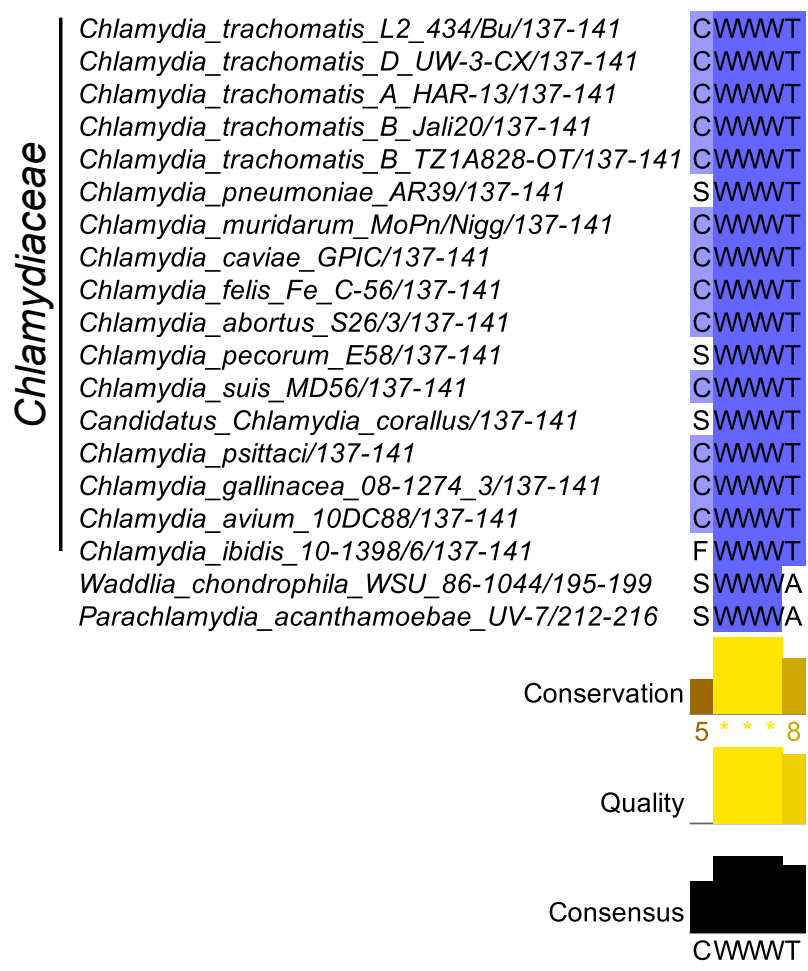

Supplementary Fig. 8 | Sequence analysis of WWW motifs across the Chlamydiales order. a, MUSCLE Multiple sequence alignment (MSA) of CTL0325 (YtgCR) across the Chlamydiales. Note that the WWW motif is well conserved across the Chlamydiaceae but poorly conserved in the environmental chlamydiae. b. Same as in a for CTL0174. Note that the WWW motif of CTL0174 is perfectly conserved even in the homolog of environmental chlamydiae. The coloration of the residues indicates the conservation across the MSA, with darker shades indicating higher conservation. Differences in the species included in each analysis reflects presence of the homolog. 
bioRxiv preprint doi: https://doi.org/10.1101/2020.05.03.075317; this version posted May 3, 2020. The copyright holder for this preprint (which was not certified by peer review) is the author/funder, who has granted bioRxiv a license to display the preprint in perpetuity. It is made available under aCC-BY-NC-ND 4.0 International license.

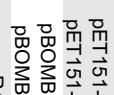

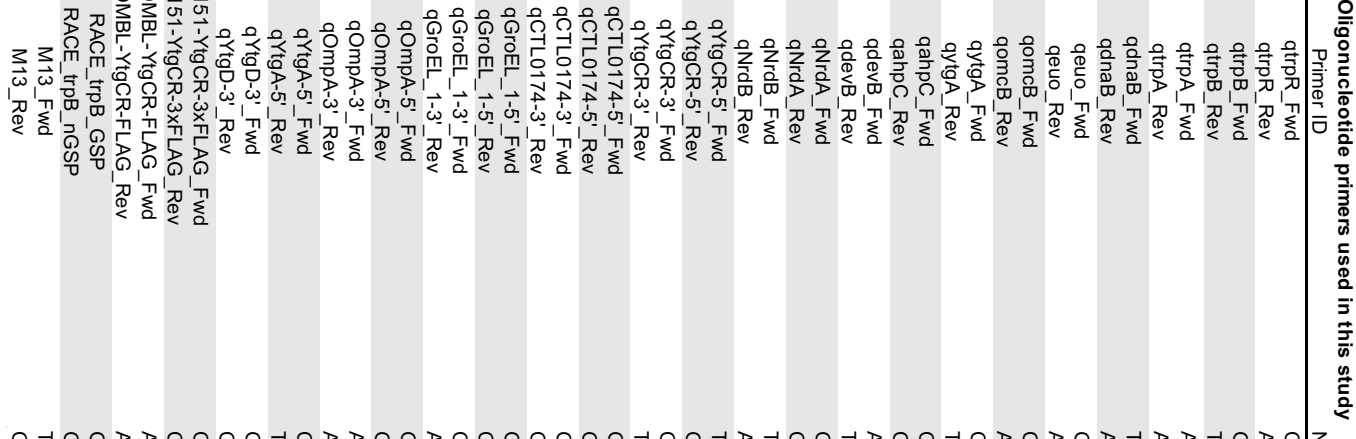

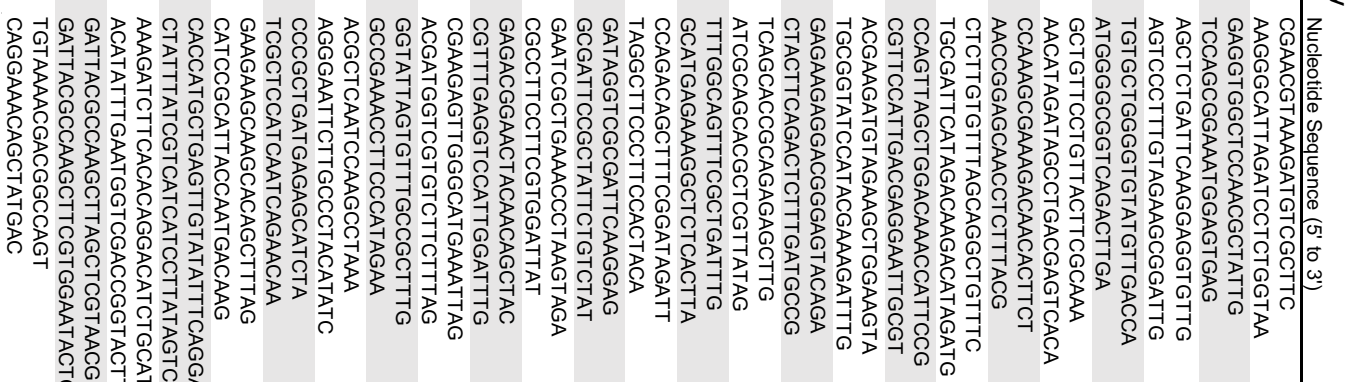

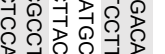

คి

กิ力

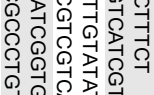

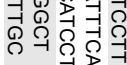

नी คे

号令

คิ

令

令

กิ

คิ

กิ่

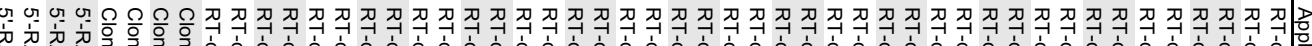

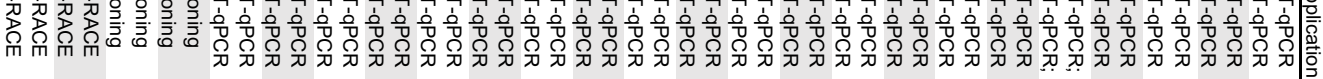
量昜

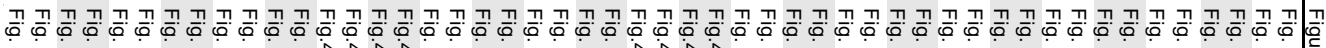

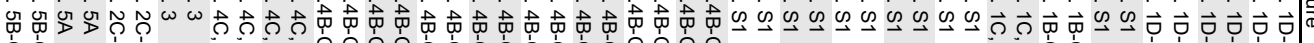

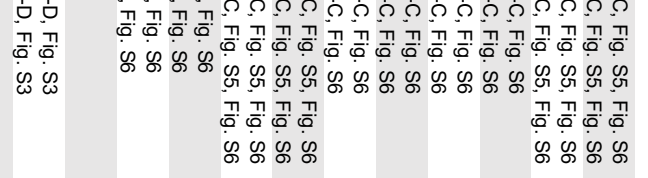

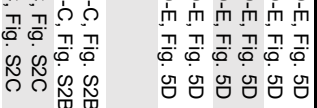

ก่ं 
bioRxiv preprint doi: https://doi.org/10.1101/2020.05.03.075317; this version posted May 3, 2020. The copyright holder for this preprint (which was not certified by peer review) is the author/funder, who has granted bioRxiv a license to display the preprint in perpetuity. It is made available under aCC-BY-NC-ND 4.0 International license.

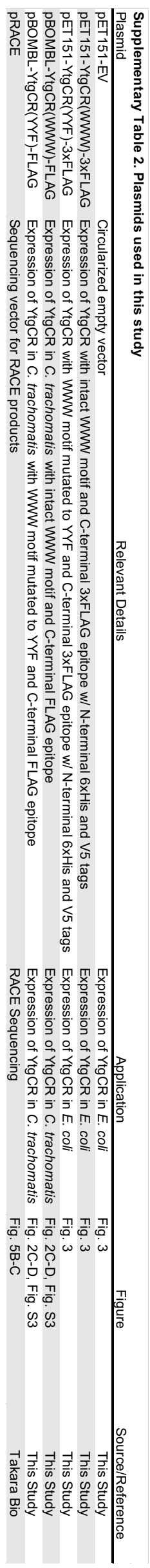

